Research Paper

\title{
Inflammatory related gene IKK $\alpha$, IKK $\beta$, IKK $\gamma$ cooperates to determine liver cancer stem cells progression by altering telomere via heterochromatin protein 1-HOTAIR axis
}

\author{
Jiahui An ${ }^{1}$, Mengying $\mathbf{W u}^{1}$, Xiaoru Xin ${ }^{1}$, Zhuojia Lin ${ }^{1}$, Xiaonan Li $^{1}$, Qidi Zheng ${ }^{1}$, Xin \\ Gui ${ }^{1}$, Tianming $\mathrm{Li}^{1}$, $\mathrm{Hu}_{\mathrm{Pu}}{ }^{1}$, Haiyan $\mathrm{Li}^{1}$, Dongdong $\mathrm{Lu}^{1}$ \\ ${ }^{1}$ School of Life Science and Technology, Tongji University, Shanghai 200092, China \\ Correspondence to: Dongdong Lu, email: ludongdong@tongji.edu.cn \\ Keywords: IKK $\alpha$, IKK $\beta$, IKK $\gamma$, telomere, HOTAIR \\ Received: March 01, $2016 \quad$ Accepted: June 13, $2016 \quad$ Published: June 29, 2016
}

\section{ABSTRACT}

Cancer stem cells are associated with tumor recurrence. IKK is a protein kinase that is composed of IKK $\alpha$, IKK $\beta$, IKK $\gamma$. Herein, we demonstrate that IKKo plus IKK $\beta$ promoted and IKK $\gamma$ inhibited liver cancer stem cell growth in vitro and in vivo. Mechanistically, IKKa plus IKK $\beta$ enhanced and IKK $\gamma$ inhibited the interplay among HP1a, HP1 $\beta$ and HP1Y that competes for the interaction among HP1a, SUZ12, HEZ2. Therefore, IKK $\alpha$ plus IKK $\beta$ inhibited and IKK $\gamma$ enhanced the activity of H3K27 methyltransferase SUZ12 and EZH2, which methylates H3K27 immediately sites on HOTAIR promoter region. Therefore, IKK $\alpha$ plus IKK $\beta$ increased and IKK $\gamma$ decreased the HOTAIR expression. Strikingly, IKK $\alpha$ plus IKK $\beta$ decreases and IKK $\gamma$ increases the HP1a interplays with DNA methyltransferase DNMT3b, which increases or decreases TERRA promoter DNA methylation. Thus IKK $\alpha$ plus IKK $\beta$ reduces and IKK $\gamma$ increases to recruit TRF1 and RNA polymerase II deposition and elongation on the TERRA promoter locus, which increases or decreases TERRA expression. Furthermore, IKKo plus IKK $\beta$ decreases/increases and IKK $\gamma$ increases/decreases the interplay between TERT and TRRRA/between TERT and TREC. Ultimately, IKK $\alpha$ plus IKK $\beta$ increases and IKK $\gamma$ decreases the telomerase activity. On the other hand, at the telomere locus, IKK $\alpha$ plus IKK $\beta$ increases/drcreases and IKK $\gamma$ decreases/increases TRF2, POT1, pPOT1, Ex01, pEx01, SNM1B, pSNM1B/CST-AAF binding, which keep active telomere regulatory genes and poised for telomere length. Strikingly, HOTAIR is required for IKK $\alpha$ plus IKK $\beta$ and IKK $\gamma$ to control telomerase activity and telomere length. These observations suggest that HOTAIR operates the action of IKK $\alpha$, IKK $\beta$, IKK $\gamma$ in liver cancer stem cells. This study provides a novel basis to elucidate the oncogenic action of IKK $\alpha$, IKK $\beta$, IKK $\gamma$ and prompts that IKK $\alpha$, IKK $\beta$, IKK $\gamma$ cooperate to HOTAR to be used as a novel therapeutic targets for liver cancer.

\section{INTRODUCTION}

I $\mathrm{B} B$ kinase (IKK) is composed of three subunits, IKK $\alpha, \operatorname{IKK} \beta$, IKK $\gamma$, where IKK $\alpha$ and IKK $\beta$ are catalytic subunits, and IKK $\gamma$ is the regulatory subunit. Many diseases are related to IKK [1]. IKK $\alpha$ has been implicated as a key regulator of oncogenesis by affecting NF-KB signaling pathways [2]. Activation of IKK- $\beta$ contributes to cancer pathogenesis and inflammatory disease [3]. IKK inhibition increases drug effectiveness in ovarian cancer [4]. IKK phosphorylation of NF- $\mathrm{\kappa B}$ contributes to acquired drug resistance in cancer [5]. Chronic alcohol exposure exacerbates inflammation and triggers pancreatic acinar-to-ductal metaplasia through PI3K/Akt/IKK [7]. IKK phosphorylates RelB to modulate its promoter specificity and promote cell migration downstream of TNF receptors [6]. Moreover, activation of NF- $\kappa B$ requires IKK $\alpha$ and IKK $\beta$ kinase activity. Protein kinase $\mathrm{C}$-associated kinase regulates NF- $\mathrm{\kappa B}$ activation through inducing IKK activation [7].

Heterochromatin protein 1 is involved in chromatin packing and epigenetic gene regulation [8]. The $\alpha, \beta$ and $\gamma$ isoforms of HP1 selectively bind to methylated lysine 9 of histone $\mathrm{H} 3$ via their chromodomains [9]. Phosphorylation 
of an HP1-like protein regulates heterochromatin body assembly for DNA elimination [10]. Emerging evidence has shown that HP1 $\alpha$ serves a biological role in cancer [11]. HP1 and the histone H3 lys9 methyltransferase $\mathrm{Su}$ (var)3-9 is requireed in stem cell self-renewal [12]. Loss of HP1 causes depletion of H3K27me3 and gain of $\mathrm{H} 3 \mathrm{~K} 27 \mathrm{me} 2$ at constitutive heterochromatin [13]. Furthermore, HP1 regulates this gene's alternative splicing by recruiting splicing factors [14].

Accumulating evidence indicates that HOTAIR plays a critical role in cancer progression. HOTAIR could promote migration and invasion of hepatocellular carcinoma (HCC) cells by inhibiting RBM38 [15]. The Polycomb group (PcG) protein heterodimer EZH2EED is necessary and sufficient for binding to the IncRNA HOTAIR [16]. Studies suggest that HOTAIR recruits chromatin-modifying complexes to specific target sequences and triggers stemness acquisition [17]. Moreover, Enforced expression of HOTAIR altered histone H3 lysine 27 methylation, gene expression, and increased cancer invasiveness in a manner dependent on Polycomb Repressive Complex 2 (PRC2) [18]. The PRC2 is composed of a trimeric core of SUZ12, EED and EZH1/2, and PRC2 catalyzes histone H3K27 trimethylation (H3K27me3), a hallmark of gene silencing [19]. H3K27 methylations contribute to the role of PRC2 in maintaining cellular growth [20].

TRF2 activity alteration is absorbing and of great concern. Our previous findings suggest that SET1A and CUDR increased TRF2 expression on the transcriptional and translational level through $\mathrm{H} 3 \mathrm{~K} 4 \mathrm{me} 3$ [21]. The shelterin protein TRF2 is essential for chromosome-end protection. Dyefunction of TRF2 causes chromosome end-to-end fusions, initiating genomic instability. Elevated levels of TRF2 induce telomeric ultrafine anaphase bridges and rapid telomere deletions [22]. Accumulating evidence suggests that the human telomerase reverse transcriptase catalytic subunit (TERT) contributes to cell to elongate telomeres [23]. The telomeric long noncoding RNA Telomeric repeat-containing RNA (TERRA) is important for telomere regulation. TERRA G-quadruplex structure is critical for binding to telomeres [24]. Moreover, TERRA participates in the regulation of telomere length, telomerase activity and heterochromatinization [25, 26]. Resaerches suggest the SNM1B/APOLLO DNA nuclease functions in resolution of replication stress and maintenance of common fragile site stability [27]. CST/ AAF, a DNA pol $\alpha$. primase accessory factor, binds POT1b and shortens the extended overhangs produced by Exo1 [28].

In this report, our findings suggest that IKK $\alpha$ plus IKK $\beta$ promoted and IKK $\gamma$ inhibited liver cancer stem cell growth in vitro and in vivo. Mechanistically, IKK $\alpha$ plus IKK $\beta$ enhanced and IKK $\gamma$ inhibited the interplay among HP $1 \alpha$, HP $1 \beta$ and HP $1 \gamma$. Therefore, IKK $\alpha$ plus IKK $\beta$ increased and IKK $\gamma$ decreased the TOTAIR expression.
Ultimately, IKK $\alpha$ plus IKK $\beta$ increases and IKK $\gamma$ decreases the telomere length and telomerase activity. Of significance, HOTAIR is required for IKK $\alpha$ plus IKK $\beta$ and IKK $\gamma$ to control telomere. This study provides a novel basis to elucidate the oncogenic action of IKK $\alpha$, IKK $\beta$, IKK $\gamma$.

\section{RESULTS}

\section{IKK $\alpha$, IKK $\beta$, IKK $\gamma$ influence on liver cancer stem cells growth in vitro}

To address whether synergy of IKK $\alpha$, IKK $\beta$, IKK $\gamma$ altered the liver cancer stem cells growth in vitro, we first constructed stable cell lines transfected with plasmid with IKK $\alpha, \operatorname{IKK} \beta, \operatorname{IKK} \gamma$. As shown in Figure 1A, the expression of CD24, CD133, Epcam is positive in eight stable cell lines (IKK $\alpha, \operatorname{IKK} \beta, \operatorname{IKK} \gamma, \operatorname{IKK} \alpha+\operatorname{IKK} \beta$, $\operatorname{IKK} \beta+\operatorname{IKK} \gamma$, IKK $\alpha+\operatorname{IKK} \gamma, \operatorname{IKK} \alpha+\operatorname{IKK} \beta+\operatorname{IKK} \gamma)$. Our results showed that IKK $\alpha$, IKK $\beta$, IKK $\gamma$ expression were increased in the senen stable cell lines $(\mathrm{IKK} \alpha$, $\operatorname{IKK} \beta, \operatorname{IKK} \gamma, \operatorname{IKK} \alpha+\operatorname{IKK} \beta, \operatorname{IKK} \beta+\operatorname{IKK} \gamma, \operatorname{IKK} \alpha+\operatorname{IKK} \gamma$, $\operatorname{IKK} \alpha+\operatorname{IKK} \beta+\mathrm{IKK} \gamma)$ than in control group respectively (Figure 1B). IKK $\alpha$ plus IKK $\beta$ overexpression accelerated the growth of liver cancer stem cells to a significantly greater extent when compared with the other cells $(\mathrm{P}<0.05$ or 0.01 ), as well as single IKK $\gamma$ overexpression inhibited the growth of liver cancer stem cells compared with the other cells ( $\mathrm{P}<0.05$ or 0.01$)$ (Figure 1C). In BrdU staining (a $\mathrm{S}$ phase cells assay), the BrdU positive cells rates were $41.2 \pm 6.7 \%, 42.7 \pm 6.9 \%, \quad 43.5 \pm 7.4 \%, 40.8 \pm 8.1 \%, 39.9 \pm 6$ $.6 \%, 41.9 \pm 5.8 \%$ in control, IKK $\alpha, \operatorname{IKK} \beta, \operatorname{IKK} \beta+\operatorname{IKK} \gamma$, IKK $\alpha+\operatorname{IKK} \gamma, \operatorname{IKK} \alpha+\operatorname{IKK} \beta+\operatorname{IKK} \gamma$ group respectively. However, the BrdU positive cells rates was $76.9 \pm 15.9 \%$ in the IKK $\alpha$ plus IKK $\beta$ overexpressed group $(\mathrm{p}<0.01)$, while only $13.2 \pm 3.1 \%$ BrdU positive cells rates was in the single IKK $\gamma$ overexpressed group $(\mathrm{p}<0.01)$ (Figure 1D). In colony-formation efficiency assay, the colonies formed-rates were $20.4 \pm 4.5 \%, 22.4 \pm 4.3 \%, 26.4 \pm 5.1 \%, 23$ $.7 \pm 3.2 \%, 21.2 \pm 4.2 \%, 25.9 \pm 5.7 \%$ in control, IKK $\alpha$, IKK $\beta$, $\operatorname{IKK} \beta+\mathrm{IKK} \gamma, \operatorname{IKK} \alpha+\operatorname{IKK} \gamma, \operatorname{IKK} \alpha+\operatorname{IKK} \beta+\operatorname{IKK} \gamma$ group respectively. However, the colonies formed-rate was $52.5 \pm 12.5 \%$ in the IKK $\alpha$ plus IKK $\beta$ overexpressed group $(\mathrm{p}<0.01)$, while only $9.1 \pm 2.1 \%$ colonies formed-rate was in the single IKK $\gamma$ overexpressed group $(\mathrm{p}<0.01)$ (Figure 1E). Taken together, IKK $\alpha$ plus IKK $\beta$ promoted and IKK $\gamma$ inhibited liver cancer stem cell growth in vitro.

\section{IKK $\alpha$, IKK $\beta$, IKK $\gamma$ influence on liver cancer stem cells growth in vivo}

To determine whether IKK $\alpha$, IKK $\beta$,
IKK $\gamma$, IKK $\alpha+\mathrm{IKK} \beta$, IKK $\beta+\mathrm{IKK} \gamma$, IKK $\alpha+\mathrm{IKK} \gamma$,
IKK $\alpha+\mathrm{IKK} \beta+\mathrm{IKK} \gamma$ could affect the tumorigenesis in vivo,
the aforementioned eight stable cell lines were injected
subcutaneously at armpit into Balb/C mice. As Expected,


significant differences in tumor weights were observed among some groups. As shown in Figure 2A, B, when IKK $\alpha$ and IKK $\beta$ were co-overexpressed, the tumor weight increased significantly compared to the control, IKK $\alpha$, IKK $\beta, \quad$ IKK $\beta+$ IKK $\gamma$, IKK $\alpha+\operatorname{IKK} \gamma$, IKK $\alpha+\operatorname{IKK} \beta+\operatorname{IKK} \gamma$ overexpression group $(1.52 \pm 0.32$ gram vs $0.75 \pm 0.15$ gram, $0.66 \pm 0.12$ gram, $0.68 \pm 0.07$ gram, $0.72 \pm 0.16$ gram, $0.69 \pm 0.12$ gram, $0.74 \pm 0.18$ gram, $\mathrm{p}<0.01$, respectively). Conversely, when single IKK $\gamma$ was only overexpressed, the tumor weight significantly compared to the control, IKK $\alpha$, $\operatorname{IKK} \beta, \operatorname{IKK} \beta+\operatorname{IKK} \gamma, \operatorname{IKK} \alpha+\operatorname{IKK} \gamma, \operatorname{IKK} \alpha+\operatorname{IKK} \beta+\operatorname{IKK} \gamma$ overexpression group $(0.21 \pm 0.05$ gram vs $0.75 \pm 0.15$ gram, $0.66 \pm 0.12$ gram, $0.68 \pm 0.07$ gram, $0.72 \pm 0.16$ gram, $0.69 \pm 0.12$ gram, $0.74 \pm 0.18$ gram, $\mathrm{p}<0.01$, respectively), and there, however, were no significant difference among control, IKK $\alpha$, $\operatorname{IKK} \beta, \quad \operatorname{IKK} \beta+\operatorname{IKK} \gamma, \operatorname{IKK} \alpha+\operatorname{IKK} \gamma, \operatorname{IKK} \alpha+\operatorname{IKK} \beta+\operatorname{IKK} \gamma$ overexpression cell lines $(\mathrm{P}>0.05)$. We also found early tumor formation in the IKK $\alpha$ and IKK $\beta$ co-overexpressed group ( $5.23 \pm 0.98$ days) and later tumor formation in single IKK $\gamma$ overexpressed group (15.12 \pm 2.34 days) compared to the control, IKK $\alpha, \operatorname{IKK} \beta$, IKK $\beta+\operatorname{IKK} \gamma, \operatorname{IKK} \alpha+\operatorname{IKK} \gamma$, $\mathrm{IKK} \alpha+\mathrm{IKK} \beta+\mathrm{IKK} \gamma$ overexpression group $(7.81 \pm 1.23$ days, $8.21 \pm 2.01$ days, $7.95 \pm 1.34$ days, $8.45 \pm 1.45$ days, $7.65 \pm 1.21$ days, $7.12 \pm 1.46$ days, $\mathrm{p}<0.01$, respectively) (Figure $2 \mathrm{C}$ ). Pathological picture (HE stain) of xenograft tumor showed that tumor tissue possessed more poor-differentiation cells and less moderately or well-differentiation cells in the IKK $\alpha$ and IKK $\beta$ co-overexpressed group, and less poor-differentiation cells and more moderately or welldifferentiation cells in single IKK $\gamma$ overexpressed group than that of control, IKK $\alpha, \operatorname{IKK} \beta, \operatorname{IKK} \beta+\operatorname{IKK} \gamma, \operatorname{IKK} \alpha+\operatorname{IKK} \gamma$, IKK $\alpha+\operatorname{IKK} \beta+\mathrm{IKK} \gamma$ overexpressed groups (Figure 2D,
A

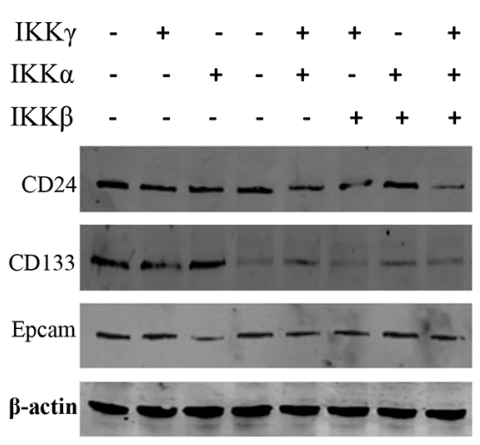

D

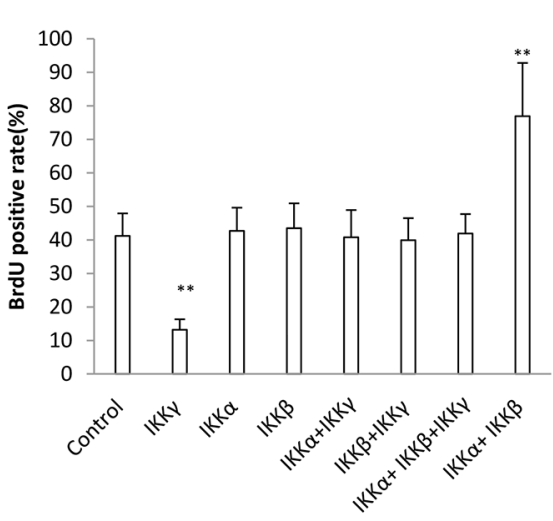

B

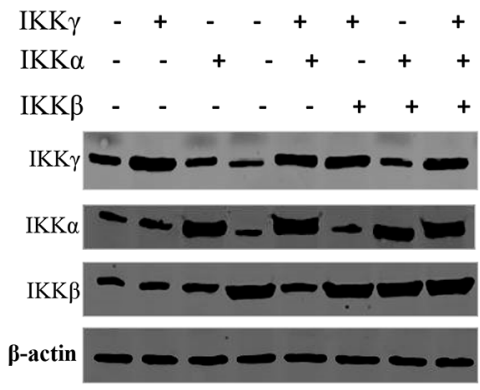

$\mathbf{E}$

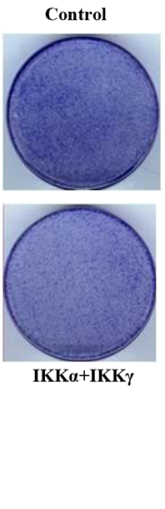

C

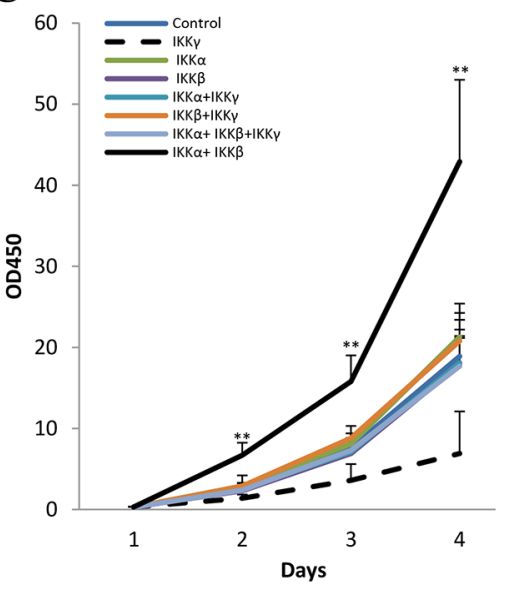

Figure 1: IKK $\alpha$, IKK $\beta$, IKK $\gamma$ influence on human liver cancer stem cells (hLCSC) growth in vitro. A. The Western blotting analysis of CD133, CD24, Epcam in stable hLCSC cell lines transfected with pcDNA3.1-IKK $\alpha$, pcDNA3.1-IKK $\beta$, pcDNA3.1IKK $\gamma$ respectively. $\beta$-actin as internal control. B. The Western blotting analysis of IKK $\alpha$, IKK $\beta$, IKK $\gamma$ in stable hLCSC cell lines transfected with pcDNA3.1-IKK $\alpha$, pcDNA3.1-IKK $\beta$, pcDNA3.1-IKK $\gamma$ respectively. $\beta$-actin as internal control. C. Cells growth assay using CCK8. Each value was presented as mean \pm standard error of the mean (SEM). Data are means of value from three independent experiments, bar \pm SEM. **,P $<0.01 ; *, P<0.05$. D. S phase cells assay using BrdU. Each value was presented as mean \pm standard error of the mean (SEM). Data are means of value from three independent experiments, bar \pm SEM. ${ }^{*}, \mathrm{P}<0.01 ; *, \mathrm{P}<0.05$. E. Cells soft agar colony formation assay. Each value was presented as mean \pm standard error of the mean (SEM). Data are means of value from three independent experiments, bar \pm SEM. **,P $<0.01 ; *, \mathrm{P}<0.05$. 
Upper). As shown in Figure 2D lower \& Figure 2E, the number of PCNA positive cells is higher in IKK $\alpha$ and IKK $\beta$ co-overexpressed group $(68.4 \pm 13.6 \%)$ and lower in single IKK $\gamma$ overexpression group (12.4 \pm 2.7 ) compared to the control, IKK $\alpha$, IKK $\beta$, IKK $\beta+\operatorname{IKK} \gamma$, IKK $\alpha+\operatorname{IKK} \gamma$, IKK $\alpha+\mathrm{IKK} \beta+\mathrm{IKK} \gamma$ overexpressed groups $(34.5 \pm 6.2 \%, 4$ $1.2 \pm 7.3 \%, 31.9 \pm 5.3 \%, 35.6 \pm 3.6 \%, 32.4 \pm 7.4 \%, 33.1 \pm 8.1 \%$, $\mathrm{p}<0.01$, respectively), and there, however, were no significant difference among control, IKK $\alpha$, IKK $\beta$, IKK $\beta+\operatorname{IKK} \gamma$, IKK $\alpha+$ IKK $\gamma$, IKK $\alpha+\operatorname{IKK} \beta+$ IKK $\gamma$ overexpressed groups $(\mathrm{P}>0.05)$. Taken together, these observations suggest IKK $\alpha$ plus IKK $\beta$ promoted and single IKK $\gamma$ inhibited liver cancer stem cell growth in vivo.

\section{IKK $\alpha$, IKK $\beta$, IKK $\gamma$ alter the methylation of HistoneH3 on lysine 27 dependent on HP1}

To prove whether IKK $\alpha$, IKK $\beta$, IKK $\gamma$ influence on the methylation of HistoneH3 on lysine 27, we performed western blotting and IP assay in these groups. As shown in Figure 3A, compared to the control, IKK $\alpha$, $\operatorname{IKK} \beta, \operatorname{IKK} \beta+\operatorname{IKK} \gamma, \operatorname{IKK} \alpha+\operatorname{IKK} \gamma, \operatorname{IKK} \alpha+\operatorname{IKK} \beta+\operatorname{IKK} \gamma$ overexpression group, the interplay among $\mathrm{HP} 1 \alpha, \mathrm{HP} 1 \beta$ and HP1 $\gamma$ was significantly increased when IKK $\alpha$ and IKK $\beta$ were co-overexpressed. Conversely, the interplay among HP $1 \alpha$, HP $1 \beta$ and HP $1 \gamma$ was significantly decreased when single IKK $\gamma$ was overexpressed. Furthermore, when HP $1 \beta$ knockdown, HP $1 \gamma$ knockdown or HP $1 \beta$ plus HP $1 \gamma$ knockdown (Figure 3B), the interplay among HP1 $\alpha, \mathrm{HP} 1 \beta$ and HP1 $\gamma$ was significantly decreased, and the unbound HP $1 \alpha$ was significantly increased in HP $1 \beta$ plus HP $1 \gamma$ knockdown group (Figure 3C). Furthermore, the interplay among SUZ12, EZH2, Histone 3 and HP1 $\alpha$ was significantly increased in HP1 $\beta$ plus HP1 $\gamma$ knockdown group (Figure 3D). Compared to the control, IKK $\alpha, \operatorname{IKK} \beta, \operatorname{IKK} \beta+\operatorname{IKK} \gamma$, IKK $\alpha+\operatorname{IKK} \gamma, \operatorname{IKK} \alpha+\operatorname{IKK} \beta+\mathrm{IKK} \gamma$ overexpression group, the interplay among SUZ12, EZH2, Histone3 and HP1 $\alpha$ was significantly decreased when IKK $\alpha$ and IKK $\beta$ were
A

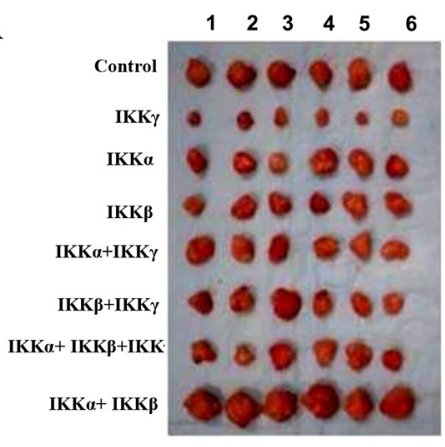

D

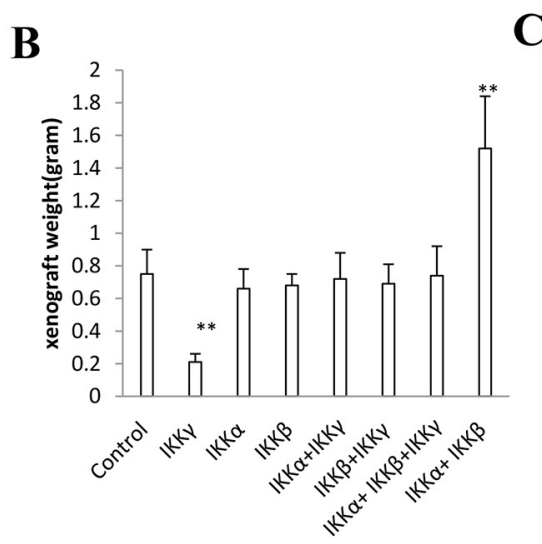

B

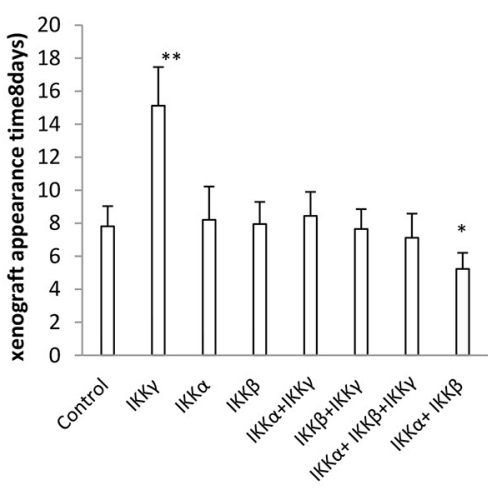

$\mathbf{E}$
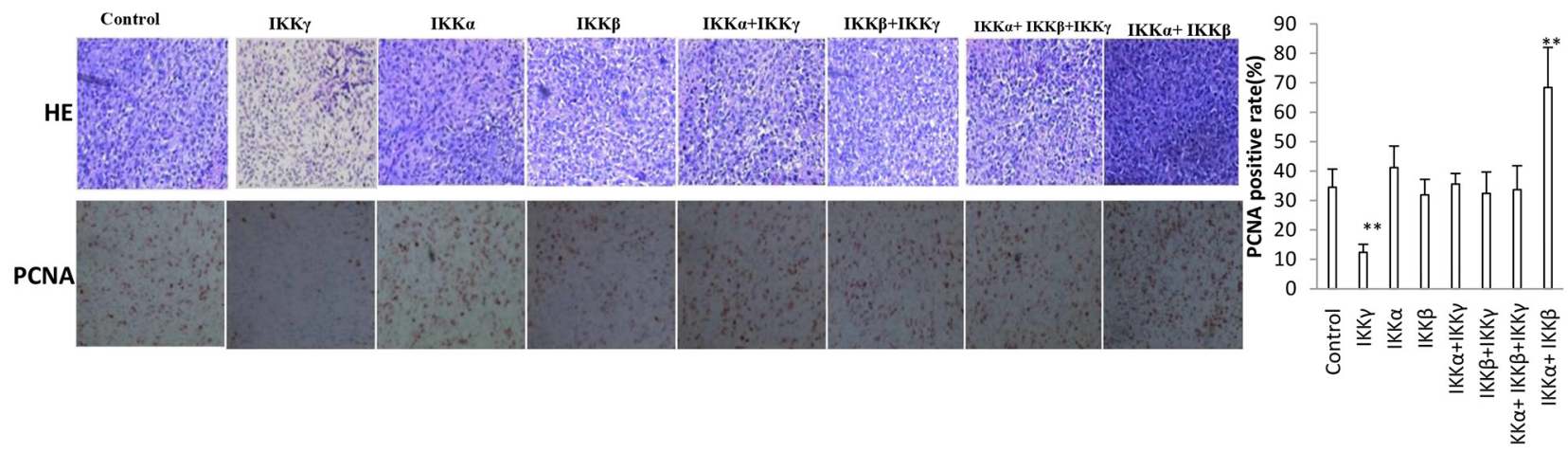

Figure 2: IKK $\boldsymbol{\alpha}$, IKK $\boldsymbol{\beta}$, IKK $\boldsymbol{\gamma}$ influence on liver cancer stem cells growth in vivo. A. The mice were stratified and the tumors were recovered. The photography of xenograft tumor in the eight groups (indicated in left). B. The wet weight of each tumor was determined for each mouse. Each value was presented as mean \pm standard error of the mean (SEM). bar \pm SEM. ${ }^{* *}, \mathrm{P}<0.01 ; *, \mathrm{P}<0.05$. C. The Xenograft appearance time (days). Each value was presented as mean \pm standard error of the mean (SEM). bar \pm SEM. ${ }^{* *}, \mathrm{P}<0.01 ; *, \mathrm{P}<0.05$. D. A portion of each tumor was fixed in $4 \%$ paraformaldehyde and embedded in paraffin for histological hematoxylin-eosin (HE) staining (upper) and anti-PCNA immunostainning (lower). (original magnification $\times 100$ ). E. PCNA positive cells analysis. Each value was presented as mean \pm standard error of the mean (SEM). bar \pm SEM. ${ }^{* *}, \mathrm{P}<0.01 ;{ }^{*}, \mathrm{P}<0.05$. 
co-overexpressed. Conversely, the interplay among SUZ12, EZH2, HistoneH 3 and HP1 $\alpha$ was significantly increased when single IKK $\gamma$ was overexpressed (Figure 3E). Significantly, compared to the control, IKK $\alpha$, $\mathrm{IKK} \beta, \quad \mathrm{IKK} \beta+\mathrm{IKK} \gamma, \mathrm{IKK} \alpha+\mathrm{IKK} \gamma, \mathrm{IKK} \alpha+\mathrm{IKK} \beta+\mathrm{IKK} \gamma$ overexpression group, the $\mathrm{H} 3 \mathrm{~K} 27 \mathrm{me}, \mathrm{H} 3 \mathrm{~K} 27 \mathrm{me} 2$ and $\mathrm{H} 3 \mathrm{~K} 27 \mathrm{me} 3$ were significantly decreased when IKK $\alpha$ and IKK $\beta$ were co-overexpressed. Conversely, the H3K27me, H3K27me2 and H3K27me3 was significantly increased when single IKK $\gamma$ was overexpressed, (Figure 3D). Moreover, the $\mathrm{H} 3 \mathrm{~K} 27 \mathrm{Ac}$ and $\mathrm{NF}-\mathrm{\kappa B}$ were significantly increased when IKK $\alpha$ and IKK $\beta$ were co-overexpressed.
Conversely, the H3K27Ac and NF- $\kappa \mathrm{B}$ were significantly increased in single IKK $\gamma$ overexpressing group (Figure 3E). Taken together, IKK $\alpha$, IKK $\beta$, IKK $\gamma$ alter the modification of Histone H3 on lysine 27 dependent on HP1.

\section{IKK $\alpha$, IKK $\beta$, IKK $\gamma$ regulate HOTAIR expression dependent on $\mathrm{H} 3 \mathrm{~K} 27 \mathrm{me} 3$}

To investigate whether $\operatorname{IKK} \alpha$, IKK $\beta$, and $\operatorname{IKK} \gamma$ influence on HOTAIR expression, we first performed IP assay in liver cancer stem cells. As shown in Figure 4A, compared to the control, IKK $\alpha$, IKK $\beta$,
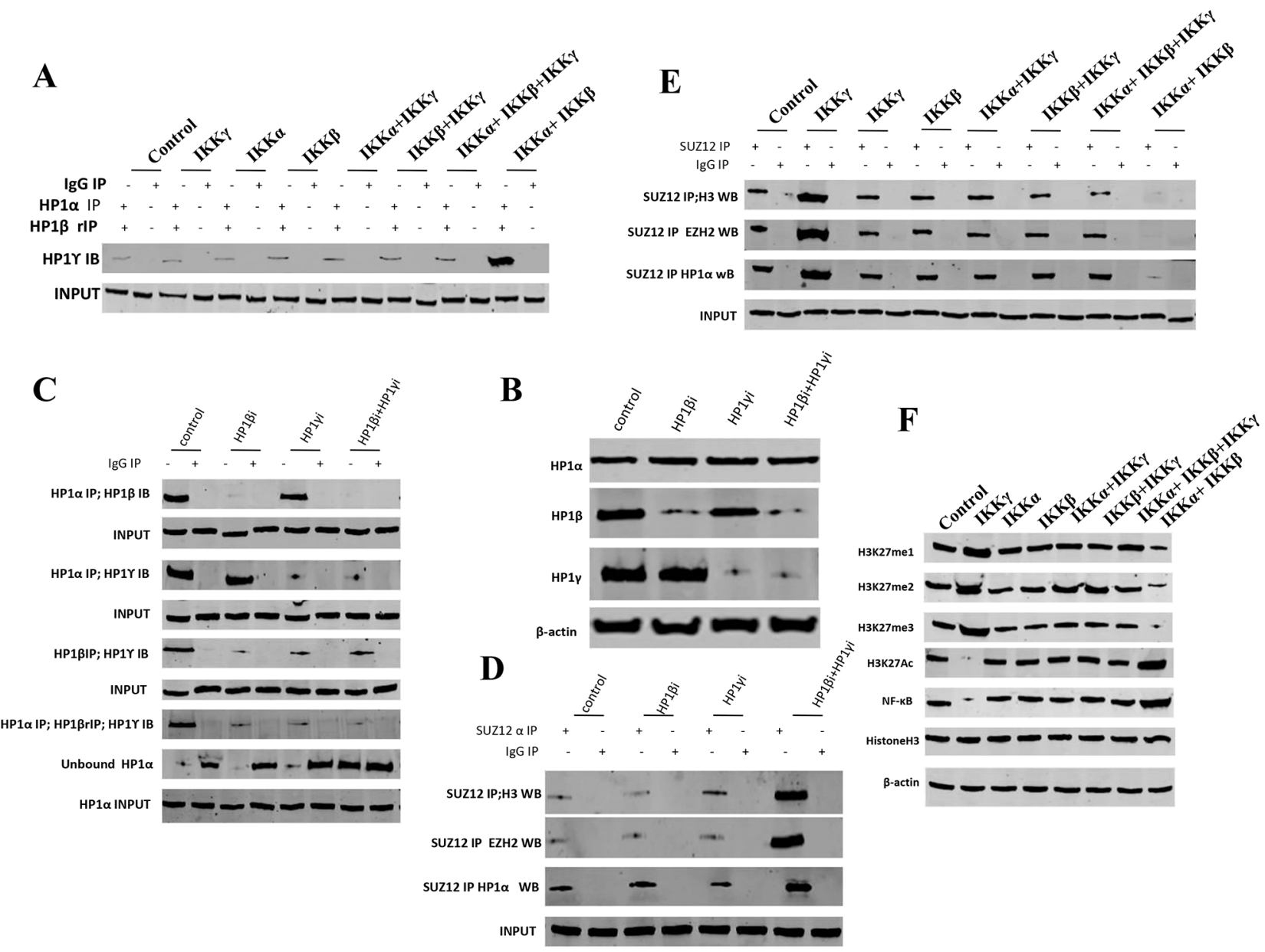

Figure 3: IKKa, IKK $\beta$, IKK $\gamma$ alter the methylation of HistoneH3 on lysine 27 dependent on HP1. A. Repeat CoImmunoprecipitation (IP) with anti-HP1 $\alpha$, anti-HP1 $\beta$ followed by western blotting with, anti-HP1 $\gamma$ in liver cancer stem cells transfected with pcDNA3.1-IKK $\alpha$, pcDNA3.1-IKK $\beta$, pcDNA3.1-IKK $\gamma$, respectively. IgG IP as negative control. Western blotting with, anti-HP1 $\gamma$ as INPUT. B. Western blotting with anti-HP1 $\alpha$, anti-HP1 $\beta$, anti-HP1 $\gamma$ in liver cancer stem cells transfected with pGFP-V-RS-HP1 $\beta$ or pGFPV-RS-HP1 $\gamma$, respectively. $\beta$-actin as internal control. C. Co-Immunoprecipitation (IP) with anti-HP1 $\alpha$ or anti-HP1 $\beta$ followed by western blotting with, anti-HP1 $\beta$ or anti-HP1 $\gamma$ in liver cancer stem cells transfected with pGFP-V-RS-HP1 $\beta$ or pGFP-V-RS-HP1 $\gamma$, respectively. IgG IP as negative control. Western blotting with anti-HP1 $\beta$ or anti-HP1 $\gamma$ as INPUT. D. Co-Immunoprecipitation (IP) with anti-SUZ12 followed by western blotting with anti-Histone H3, anti-EZH2, anti-HP1 $\alpha$ in liver cancer stem cells transfected with pGFP-V-RS-HP1 $\beta$ or pGFP-V-RS-HP1 $\gamma$, respectively. IgG IP as negative control. Western blotting with anti-SUZ12 as INPUT. E. Co-Immunoprecipitation (IP) with anti-SUZ12 followed by western blotting with anti-Histone H3, anti-EZH2, anti-HP1 $\alpha$ in liver cancer stem cells transfected with pcDNA3.1-IKK $\alpha$, pcDNA3.1-IKK $\beta$, pcDNA3.1-IKK $\gamma$. respectively. IgG IP as negative control. Western blotting with anti-SUZ12 as INPUT. F. Western blotting with anti-H3K27me1, anti-H3K27me2, anti-H3K27me3, anti-H3K27Ac, anti-NFKB and anti-H3 in liver cancer stem cells transfected with pcDNA3.1-IKK $\alpha$, pcDNA3.1-IKK $\beta$, pcDNA3.1-IKK $\gamma$, respectively. $\beta$-actin as internal control. 
$\mathrm{IKK} \beta+\mathrm{IKK} \gamma, \quad \mathrm{IKK} \alpha+\mathrm{IKK} \gamma, \quad \mathrm{IKK} \alpha+\mathrm{IKK} \beta+\mathrm{IKK} \gamma$ overexpression group, when IKK $\alpha$ and IKK $\beta$ were co-overexpressed, the interplay between HP1 $\alpha$ and H3K27me1/2/3 was significantly decreased. Conversely, when single IKK $\gamma$ was overexpressed, the interplay between HP1 $\alpha$ and $\mathrm{H} 3 \mathrm{~K} 27 \mathrm{me} 3$ was significantly decreased. Furthermore, the loadeing of H3K27me3 onto the HOTAIR promoter region was significantly decreased when IKK $\alpha$ and IKK $\beta$ were co-overexpressed. Conversely, when single IKK $\gamma$ was overexpressed, the loading of H3K27me3 onto the HOTAIR promoter region was significantly decreased (Figure 4B). However, the action was abolished when HP1 $\alpha$ was knocked down in these liver cancer stem cells (Figure $4 \mathrm{C}$ ). As shown in Figure 4D, compared to the control, IKK $\alpha$, $\operatorname{IKK} \beta, \operatorname{IKK} \beta+\operatorname{IKK} \gamma, \operatorname{IKK} \alpha+\operatorname{IKK} \gamma, \operatorname{IKK} \alpha+\operatorname{IKK} \beta+\operatorname{IKK} \gamma$ overexpression group, the HOTAIR promoter luciferase activity was significantly increased when IKK $\alpha$ and IKK $\beta$ were co-overexpressed. Conversely, the HOTAIR promoter luciferase activity was significantly decreased when single IKK $\gamma$ was overexpressed. As shown in Figure 4E, when IKK $\alpha$ and IKK $\beta$ were co-overexpressed, the HOTAIR exptression was significantly increased. Conversely, when single IKK $\gamma$ was overexpressed, the HOTAIR experssion was significantly decreased. Taken together, IKK $\alpha$, IKK $\beta$, and IKK $\gamma$ regulate HOTAIR expression dependent on H3K27me3.

\section{IKK $\alpha$, IKK $\beta$, and IKK $\gamma$ control telomerase activity}

To investigate whether IKK $\alpha$, IKK $\beta$, IKK $\gamma$ influence on telomere, we first consider to analyse the
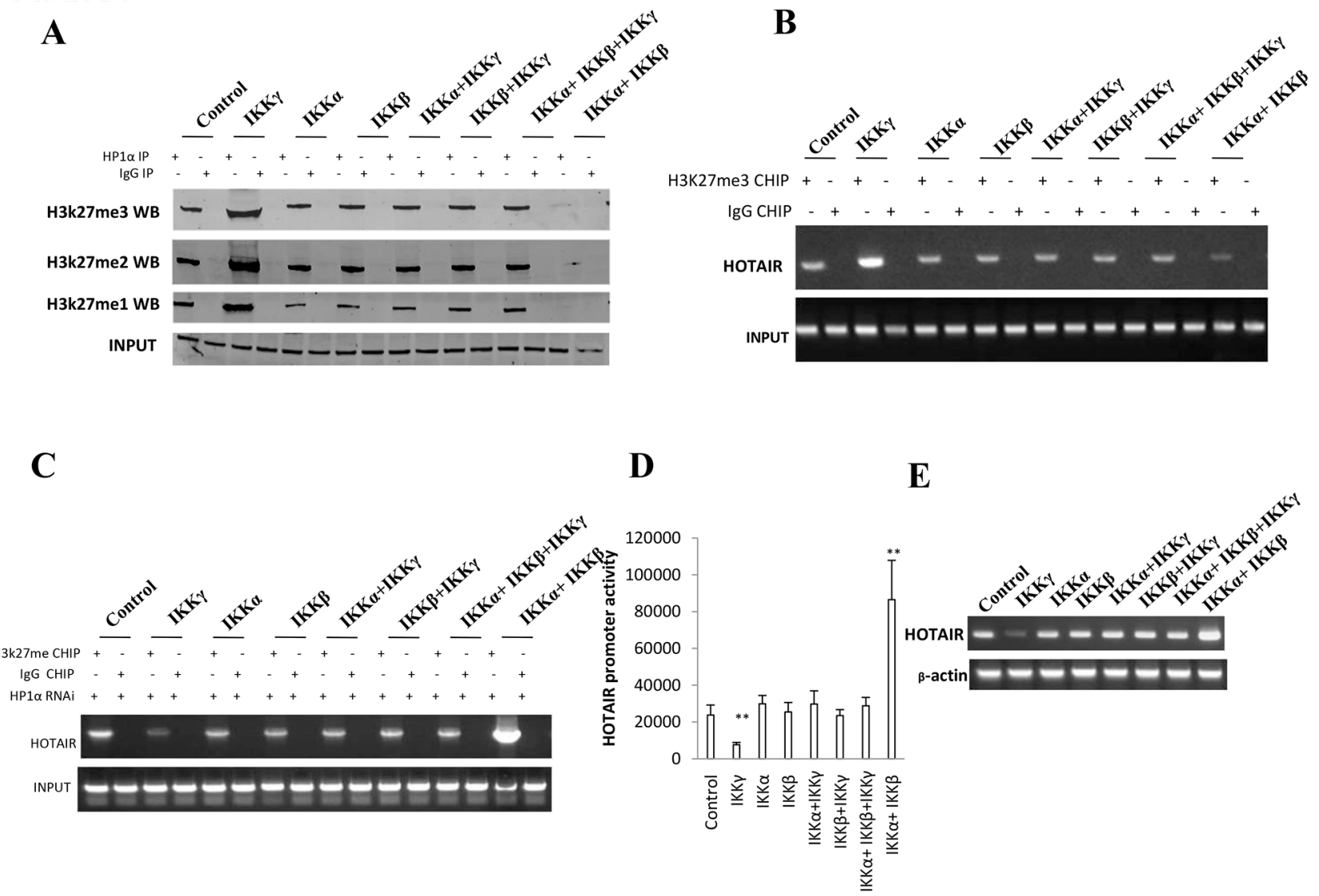

Figure 4: IKK $\alpha$, IKK $\beta$, IKK $\gamma$ regulate HOTAIR expression dependent on H3K27me3. A. Co-Immunoprecipitation (IP) with anti-HP1 $\alpha$ followed by western blotting with, anti-H3K27me1, anti-H3K27me2, anti-H3K27me3 in liver cancer stem cells transfected with pcDNA3.1-IKK $\alpha$, pcDNA3.1-IKK $\beta$, pcDNA3.1-IKK $\gamma$ respectively. IgG IP as negative control. Western blotting with anti-HP1 $\alpha$ as INPUT. B. Chromatin Immunoprecipitation (CHIP) with anti-H3K27me3 followed by PCR with HOTAIR promoter primers in liver cancer stem cells transfected with pcDNA3.1-IKK $\alpha$, pcDNA3.1-IKK $\beta$, pcDNA3.1-IKK $\gamma$ respectively. IgG CHIP as negative control. PCR for HOTAIR promoter as INPUT. C. Chromatin Immunoprecipitation (CHIP) with anti-H3K27me3 followed by PCR with HOTAIR promoter primers in HP1 $\alpha$ depleted liver cancer stem cells transfected with pcDNA3.1-IKK $\alpha$, pcDNA3.1-IKK $\beta$, pcDNA3.1-IKK $\gamma$ respectively. IgG CHIP as negative control. PCR for HOTAIR promoter as INPUT. D. HOTAIR promoter luciferase activity assay in liver cancer stem cells transfected with pcDNA3.1-IKK $\alpha$, pcDNA3.1-IKK $\beta$, pcDNA3.1-IKK $\gamma$, respectively. Data represent mean $\pm \mathrm{SEM}, \mathrm{n}=3, * * \mathrm{p}<0.01$, ${ }^{*} \mathrm{p}<0.05$ represents difference significane. E. RT-PCR with HOTAIR primers in liver cancer stem cells transfected with pcDNA3.1-IKK $\alpha$, pcDNA3.1-IKK $\beta$, pcDNA3.1-IKK $\gamma$ respectively. $\beta$-actin as internal control. 
alteration of telomerase activity. As shown in Figure $5 \mathrm{~A}$, compared to the control, IKK $\alpha$, IKK $\beta, \operatorname{IKK} \beta+\mathrm{IKK} \gamma$, $\mathrm{IKK} \alpha+\mathrm{IKK} \gamma, \mathrm{IKK} \alpha+\mathrm{IKK} \beta+\mathrm{IKK} \gamma$ overexpression group, the interplay between RNAPolIII and TRF1, DNMT3b and HP1 $\alpha$ were significantly increased when IKK $\alpha$ and IKK $\beta$ were co-overexpressed,. Conversely, the interplay between RNAPolIII and TRF1, DNMT3b and HP1 $\alpha$ were significantly decreased when single IKK $\gamma$ was overexpressed. Moreover, the interplay between TERRA promoter DNA probe and DNMT3b was significantly increased, and the interplay between TERRA promoter
DNA probe and RNAPolIII, TRF1 were significantly decreased when IKK $\alpha$ and IKK $\beta$ were co-overexpressed. Conversely, when single IKK $\gamma$ was overexpressed, the interplay between TERRA promoter DNA probe and DNMT3b was significantly decreased, and the interplay between TERRA promoter DNA probe and RNAPolIII, TRF1 were significantly increased (Figure 5B). Furthermore, the loading of DNMT3b on the TERRA promoter region was significantly increased, and the loading of RNAPolIII, TRF1 on the TERRA promoter region were significantly decreased when

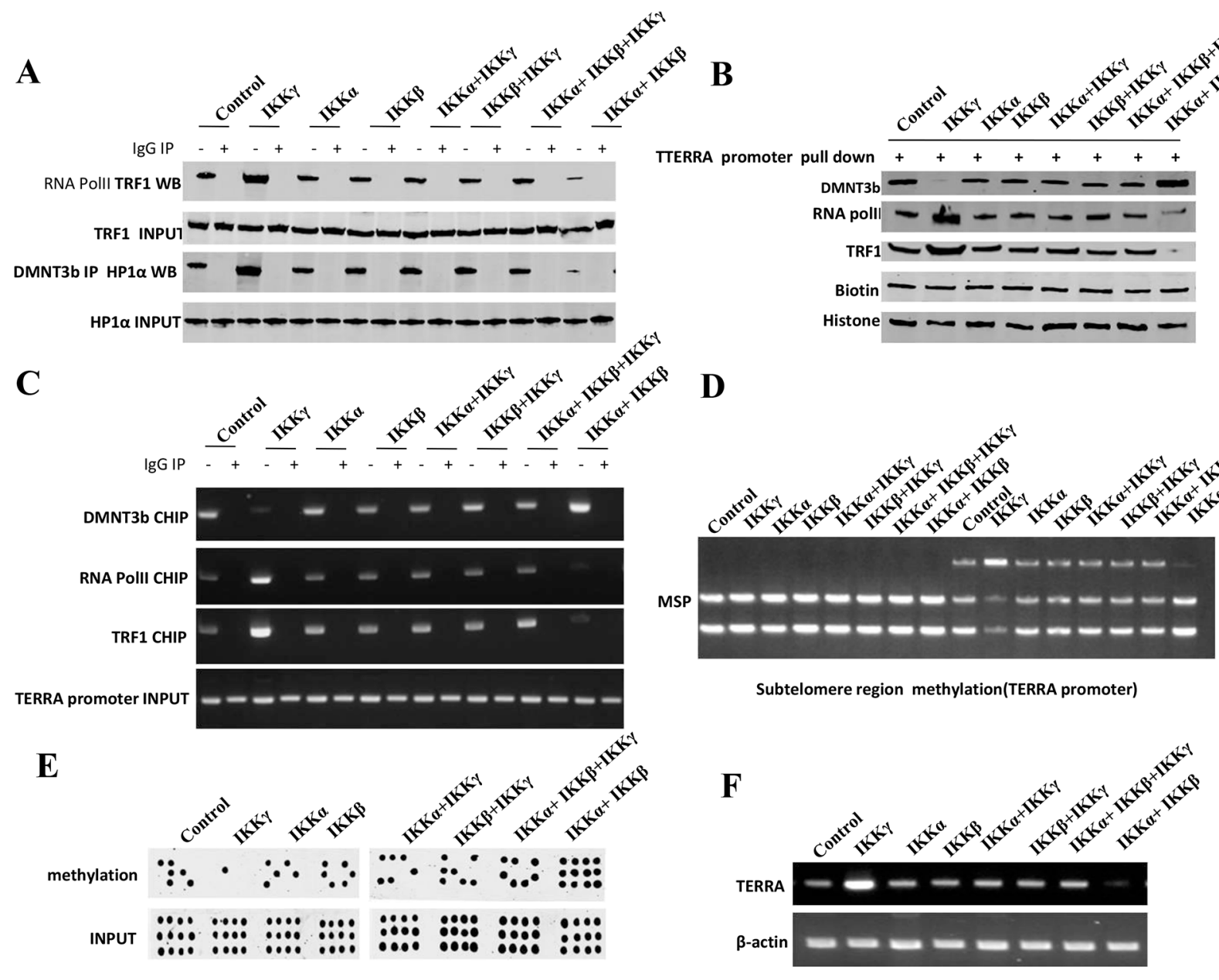

Figure 5: IKK $\alpha$, IKK $\beta$ and IKK $\gamma$ regulate TERRA expression. A. Co-Immunoprecipitation (IP) with anti-RNA polII or antiDNMT3b followed by western blotting with, anti-TRF1 or anti-HP1 $\alpha$ in liver cancer stem cells transfected with pcDNA3.1-IKK $\alpha$, pcDNA3.1-IKK $\beta$, pcDNA3.1-IKK $\gamma$ respectively. IgG IP as negative control. Western blotting with anti-TRF1 or anti-HP1 $\alpha$ as INPUT. B. Biotin-TERRA promoter DNA pulldown followed by Western blotting with anti-DNMT3b, anti-TRF1, anti-RNA polII in liver cancer stem cells transfected with pcDNA3.1-IKK $\alpha$, pcDNA3.1-IKK $\beta$, pcDNA3.1-IKK $\gamma$ respectively. Biotin as INPUT and Histone as internal control. C. Chromatin Immunoprecipitation (CHIP) with anti-DNMT3b, anti-TRF1, anti-RNA polII followed by PCR with TERRA promoter primers in liver cancer stem cells transfected with pcDNA3.1-IKK $\alpha$, pcDNA3.1-IKK $\beta$, pcDNA3.1-IKK $\gamma$ respectively. IgG CHIP as negative control. PCR for TERRA promoter as INPUT. D. TREEA promoter (Subtelomere region) methylation analysis by MspI plus BamHI digestion in liver cancer stem cells transfected with pcDNA3.1-IKK $\alpha$, pcDNA3.1-IKK $\beta$, pcDNA3.1-IKK $\gamma$ respectively. E. TERRA promoter methylation analysis by Methylated DNA Immunoprecipitation (MeDIP)-Dot blot-western blotting with anti-5-Methylcytosine $(5-\mathrm{mC})$ in expression in liver cancer stem cells transfected with pcDNA3.1-IKK $\alpha$, pcDNA3.1-IKK $\beta$, pcDNA3.1-IKK $\gamma$ respectively. F. RTPCR with TERRA primers in liver cancer stem cells transfected with pcDNA3.1-IKK $\alpha$, pcDNA3.1-IKK $\beta$, pcDNA3.1-IKK $\gamma$ respectively. $\beta$-actin as internal control. 
IKK $\alpha$ and IKK $\beta$ were co-overexpressed. Conversely, the loading of DNMT3b on the TERRA promoter region was significantly decreased, and the loading of RNAPolIII, TRF1 on the TERRA promoter region were significantly increased when only IKK $\gamma$ was overexpressed (Figure $5 C)$. Thereby, the methylation of the TERRA promoter region was significantly increased when IKK $\alpha$ and IKK $\beta$ were co-overexpressed. Conversely, the methylation of the TERRA promoter region was significantly decreased when single IKK $\gamma$ was overexpressed (Figure 5D\&5E). Furthermore, the expression of the TERRA promoter region was significantly decreased when IKK $\alpha$ and IKK $\beta$ were co-overexpressed. Conversely, the expression of the TERRA promoter region was significantly increased when single IKK $\gamma$ was overexpressed (Figure 5F). Moreover, compared to the control compared to the control, IKK $\alpha$, IKK $\beta, \operatorname{IKK} \beta+\mathrm{IKK} \gamma, \operatorname{IKK} \alpha+\mathrm{IKK} \gamma, \operatorname{IKK} \alpha+\mathrm{IKK} \beta+\mathrm{IKK} \gamma$ overexpression group, the interplay between TERRA probe and TERT was significantly decreased when IKK $\alpha$ and IKK $\beta$ were co-overexpressed,. Conversely, the interplay between TERRA probe and TERT was significantly increased when single IKK $\gamma$ overexpressed (Figure 6A). The interplay between TERRA and TERT was significantly decreased, and the interplay between TERC and TERT was significantly increased when IKK $\alpha$ and IKK $\beta$ were co-overexpressed. Conversely, the interplay between TERRA and TERT was significantly increased, and the interplay between TERC and TERT was significantly decreased when single IKK $\gamma$ was overexpressed, (Figure 6B). Significantly, the telomerase activity was significantly increased when IKK $\alpha$ and IKK $\beta$ were co-overexpressed. Conversely, the telomerase activity was significantly decreased when single IKK $\gamma$ was overexpressed, (Figure 6C). Taken together, IKK $\alpha$, IKK $\beta$, and IKK $\gamma$ control telomerase activity in liver cancer stem cells.
A

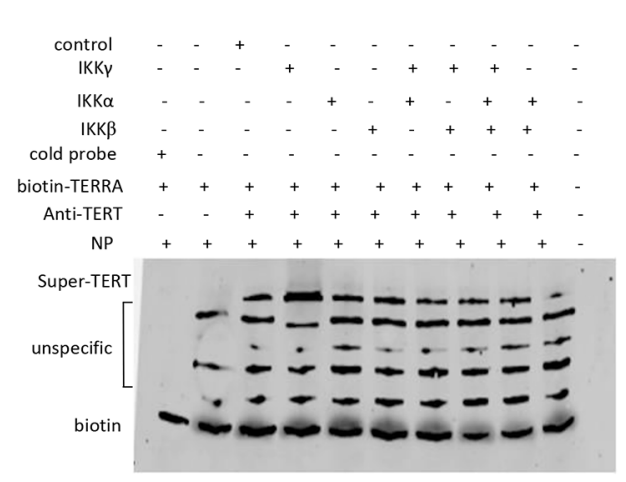

B

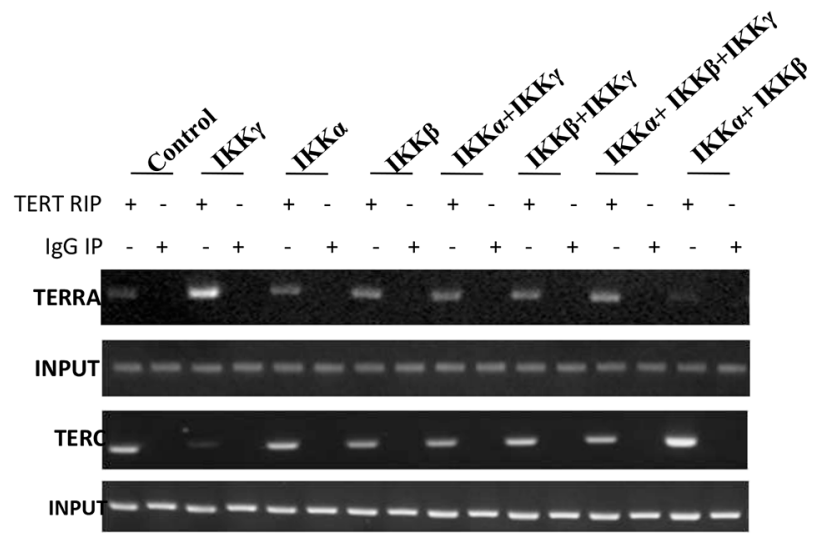

C

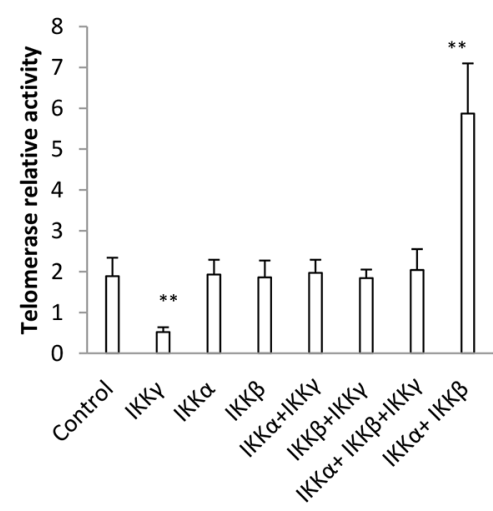

Figure 6: IKK $\boldsymbol{\alpha}$, IKK $\boldsymbol{\beta}$, IKK $\gamma$ control telomerase activity. A. Super-EMSA assay with anti-TERT and biotin-TERRA probe in primers in liver cancer stem cells transfected with pcDNA3.1-IKK $\alpha$, pcDNA3.1-IKK $\beta$, pcDNA3.1-IKK $\gamma$ respectively. Biotin as control. B. RNA Immunoprecipitation (RIP) with anti-TERT followed by RT-PCR with TERC and TERRA primers in liver cancer stem cells transfected with pcDNA3.1-IKK $\alpha$, pcDNA3.1-IKK $\beta$, pcDNA3.1-IKK $\gamma$ respectively. IgG RIP as negative control. RT-PCR for TERC or TERRA as INPUT. C. Telomerase activity assay with TRAP method primers in liver cancer stem cells transfected with transfected with pcDNA3.1-IKK $\alpha$, pcDNA3.1-IKK $\beta$, pcDNA3.1-IKK $\gamma$ respectively. Each value was presented as mean \pm standard error of the mean (SEM). $* *, \mathrm{P}<0.01$. 


\section{IKK $\alpha$, IKK $\beta$, and IKK $\gamma$ alter telomere length}

To explore whether IKK $\alpha$, IKK $\beta$, and IKK $\gamma$ influence on telomere, we also detected the alteration of telomere length in these liver cancer stem cell. As shown in Figure 7A, compared to the control compared to the control, IKK $\alpha$, IKK $\beta$, IKK $\beta+\operatorname{IKK} \gamma$, IKK $\alpha+\operatorname{IKK} \gamma$, IKK $\alpha+\operatorname{IKK} \beta+\mathrm{IKK} \gamma$ overexpression group, the interplay between the telomere DNA probe and POT1, Exo1, SNM1b, TRF2 were significantly increased, and the interplay between the telomere DNA probe and CST/AAF was significantly decreased when IKK $\alpha$ and IKK $\beta$ were co-overexpressed,. Conversely, the interplay between the telomere DNA probe and POT1, Exo1, SNM1b, TRF2 were significantly decreased, and the interplay between the telomere DNA probe and CST/AAF was significantly increased when single IKK $\gamma$ was overexpressed,. Furthermore, the loading of POT1, Exo1, SNM1b, TRF2 on the telomere DNA were significantly increased when IKK $\alpha$ and IKK $\beta$ were co-overexpressed. Conversely, the loading of POT1, Exo1, SNM1b, TRF2 on the telomere DNA were significantly decreased when single IKK $\gamma$ was overexpressed, (Figure 7B). The interplay between the telomere DNA probe and TRF2 were significantly increased when IKK $\alpha$ and IKK $\beta$ were co-overexpressed. Conversely, the interplay between the telomere DNA probe and TRF2 were significantly decreased when single IKK $\gamma$ was overexpressed, (Figure 7C). Finally, compared to the control, IKK $\alpha, \operatorname{IKK} \beta, \operatorname{IKK} \beta+\operatorname{IKK} \gamma, \operatorname{IKK} \alpha+\operatorname{IKK} \gamma$, IKK $\alpha+\operatorname{IKK} \beta+\mathrm{IKK} \gamma$ overexpression group, the telomere length was significantly increased when IKK $\alpha$ and IKK $\beta$ were co-overexpressed. Conversely, the telomere

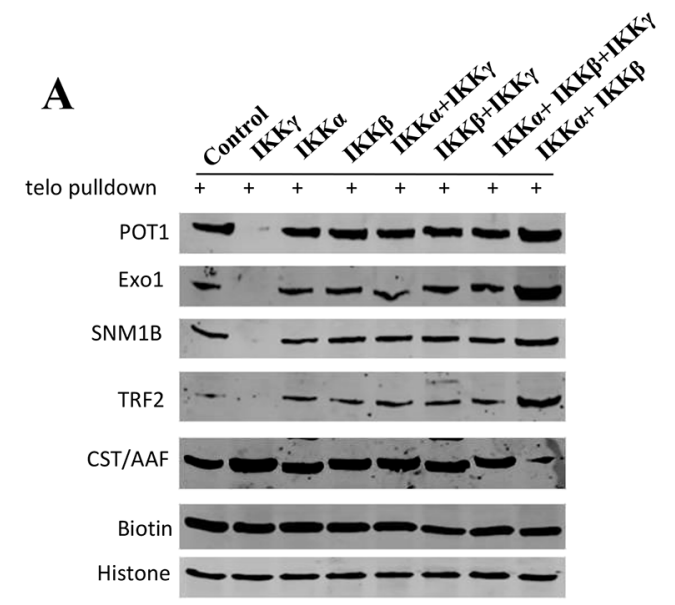

C

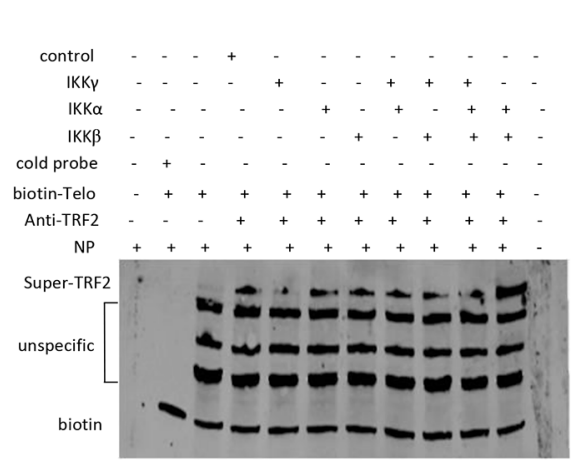

D

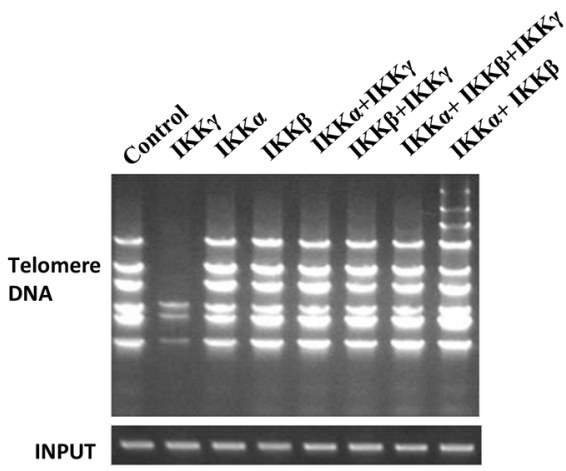

E

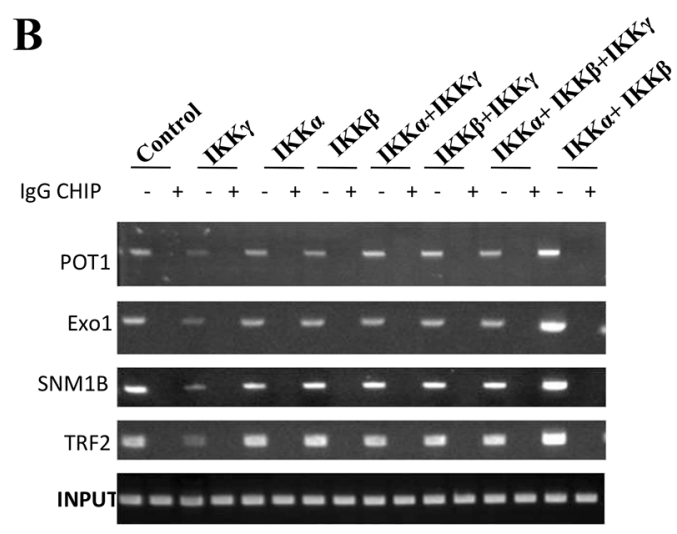

Figure 7: IKKa, IKK $\boldsymbol{\beta}$ and IKK $\gamma$ alter telomere length. A. Biotin-Telomere DNA pulldown followed by Western blotting with anti-POT1, anti-Exo1, anti-SNM1B, anti-TRF2, anti-CST/AAF in liver cancer stem cells transfected with pcDNA3.1-IKK $\alpha$, pcDNA3.1IKK $\beta$, pcDNA3.1-IKK $\gamma$ respectively. Biotin as INPUT and Histone as internal control. B. Chromatin Immunoprecipitation (CHIP) with anti-POT1, anti-Exo1, anti-SNM1B, anti-TRF2 followed by PCR with Telomere DNA primers in liver cancer stem cells transfected with pcDNA3.1-IKK $\alpha$, pcDNA3.1-IKK $\beta$, pcDNA3.1-IKK $\gamma$ respectively. IgG CHIP as negative control. PCR for Ttelomere DNA promoter as INPUT. C. Super-EMSA assay with anti-TRF2 and biotin-Ttelomere DNA probe in primers in liver cancer stem cells transfected with pcDNA3.1-IKK $\alpha$, pcDNA3.1-IKK $\beta$, pcDNA3.1-IKK $\gamma$ respectively. Biotin as control. D. The PCR detection of telomere repeat sequence in liver cancer stem cells transfected with pcDNA3.1-IKK $\alpha$, pcDNA3.1-IKK $\beta$, pcDNA3.1-IKK $\gamma$ respectively. E. The real-time PCR detection of telomere length primers in liver cancer stem cells transfected with pcDNA3.1-IKK $\alpha$, pcDNA3.1-IKK $\beta$, pcDNA3.1-IKK $\gamma$, respectively. Each value was presented as mean \pm standard error of the mean (SEM). ${ }^{* *}, \mathrm{P}<0.01$. 
length was significantly decreased when single IKK $\gamma$ was overexpressed, (Figure 7D\&7E). Collectively, these findings suggest that IKK $\alpha$ plus IKK $\beta$ increases and IKK $\gamma$ decreases the telomere length in the liver cancer stem cells.

\section{HOTAIR depletion blocks function of IKKa, IKK $\beta$, and IKK $\gamma$}

To determine whether HOTAOR regulated the IKK $\alpha$, IKK $\beta$, and IKK $\gamma$ 's function on telomeres, we performed rescued-test in liver cancer stem cells. As showed in the Figure 8A, compared to the control, the TERT expression was significantly increased, and the TERRA expression was significantly decreased when IKK $\alpha$ and IKK $\beta$ were co-overexpressed. However, the IKK $\alpha$ plus IKK $\beta$ function was fully abrogated when HOTAIR was knocked down. Conversely, when single IKK $\gamma$ was overexpressed, the TERT expression was significantly decreased, and the TERRA expression was significantly dincreased. However, the IKK $\gamma$ function was fully abrogated when HOTAIR was overexpressed. Furthermore, compared to the control group, when IKK $\alpha$ and IKK $\beta$ were cooverexpressed, the interaction between TERT and TERC was significantly increased, and the interaction between TRET andTERRA, DNMT3b and HP1 $\alpha$, RNAPolIII and TRF1 were significantly decreased. However, the IKK $\alpha$ plus IKK $\beta$ functions were fully abrogated when HOTAIR was knocked down. Conversely, when single IKK $\gamma$ was overexpressed, the interaction between TERT and TERC was significantly decreased, and the interaction between TRET and TERRA, DNMT3b and HP1 $\alpha$, RNAPolIII and TRF1 were significantly increased. However, the IKK $\gamma$ function was fully abrogated when HOTAIR was overexpressed (Figure 8B). Intriguingly, HOTAIR depletion decreased the interplay between TERT and TERC, CST/AAF and telomere, increased the interaction between TERRA and TERT, TRF2 and telomere. However, compared to the IKK $\alpha, \operatorname{IKK} \beta, \operatorname{IKK} \beta+\operatorname{IKK} \gamma$, IKK $\alpha+\operatorname{IKK} \gamma, \operatorname{IKK} \alpha+\operatorname{IKK} \beta+\operatorname{IKK} \gamma$ overexpression group, the interplay between TERT and TERC, TERRA and TERT, TRF2 and telomere, CST/AAF and telomere were significantly not altered when IKK $\alpha$ plus IKK $\beta$ or IKK $\gamma$ were overexpressed in HOTAIR knocked-down liver cancer stem cells (Figure 8C). Ultimately, the telomerase activity and telomere length expression were significantly increased when IKK $\alpha$ and IKK $\beta$ were cooverexpressed. However, the IKK $\alpha$ plus IKK $\beta$ function was fully abrogated when HOTAIR was knocked down. Conversely, when single IKK $\gamma$ was overexpressed, the telomerase activity and telomere length expression were significantly decreased. However, the IKK $\gamma$ function was fully abrogated when HOTAIR was overexpressed (Figure 8D\&8E). Taken together, HOTAIR is required for IKK $\alpha$ plus IKK $\beta$ and IKK $\gamma$ to control telomerase activity and telomere length in liver cancer stem cells.
HOTAIR operates the oncogenic action of IKKa, IKK $\beta$, and IKK $\gamma$

To address whether HOTAIR controls the synergy action of IKK $\alpha$, IKK $\beta$, and IKK $\gamma$, we constructed stable cell lines transfected with plasmid with IKK $\alpha$, IKK $\beta$, IKK $\gamma$ together with HOTAIR knocked down. As shown in Figure 9A, IKK $\alpha$, IKK $\beta$, IKK $\gamma$ expression were increased in the seven stable cell lines $(\mathrm{IKK} \alpha$, $\operatorname{IKK} \beta, \operatorname{IKK} \gamma, \operatorname{IKK} \alpha+\operatorname{IKK} \beta, \operatorname{IKK} \beta+\operatorname{IKK} \gamma, \operatorname{IKK} \alpha+\operatorname{IKK} \gamma$, $\operatorname{IKK} \alpha+\operatorname{IKK} \beta+\mathrm{IKK} \gamma$ ) than in control group respectively. HOTAIR was knocked down in the stable cell lines (IKK $\alpha$, $\operatorname{IKK} \beta, \operatorname{IKK} \gamma, \operatorname{IKK} \alpha+\operatorname{IKK} \beta, \operatorname{IKK} \beta+\operatorname{IKK} \gamma, \operatorname{IKK} \alpha+\operatorname{IKK} \gamma$, IKK $\alpha+$ IKK $\beta+$ IKK $\gamma$ ). TERT expression was reduced and TERRA expression was increased in the HOTAIR knocked down cells. TERC expression was not altered in these cell lines. Although HOTAIR depletion inhibited the cell growth $(\mathrm{P}<0.01)$, IKK $\alpha$ plus IKK $\beta$ overexpression did not accelerate and IKK $\gamma$ overexpression did not inhibit the cell growth when compared to the other cells (IKK $\alpha$, $\operatorname{IKK} \beta, \operatorname{IKK} \gamma, \operatorname{IKK} \alpha+\operatorname{IKK} \beta, \operatorname{IKK} \beta+\operatorname{IKK} \gamma, \operatorname{IKK} \alpha+\operatorname{IKK} \gamma$, IKK $\alpha+$ IKK $\beta+$ IKK $\gamma$ ) after the HOTAIR was knocked down $(\mathrm{P}>0.05)$ (Figure 9B). Although HOTAIR depletion inhibited the cell colony formation ability $(32.2 \pm 8.1 \%$ vs $9.3 \pm 2.1 \%, \quad 11.2 \pm 2.3 \%, \quad 13.5 \pm 1.9 \%, \quad 10.2 \pm 2.4 \%$, $12.6 \pm 3.1 \%, 11.8 \pm 2.6 \%, 14.9 \pm 3.3 \%$, respectively $\mathrm{P}<0.01$ ), IKK $\alpha$ plus IKK $\beta$ overexpression and IKK $\gamma$ overexpression did not alter cell colony ability in HOTAIR depleted cells groups (IKK $\alpha, \operatorname{IKK} \beta$, IKK $\gamma$, IKK $\alpha+\operatorname{IKK} \beta$, IKK $\beta+\operatorname{IKK} \gamma$, IKK $\alpha+I K K \gamma$, IKK $\alpha+\operatorname{IKK} \beta+$ IKK $\gamma)(\mathrm{P}>0.05)$ (Figure 9C). Furthermore, although HOTAIR depletion inhibited the xenograft tumor formation $(0.65 \pm 0.15$ gram vs $0.21 \pm 0.05$ gram, $0.24 \pm 0.06$ gram, $0.2 \pm 0.03$ gram, $0.23 \pm 0.0$ gram, $0.19 \pm 0.02$ gram, $0.25 \pm 0.06$ gram, $0.26 \pm 0.05$ gram, respectively, $\mathrm{P}<0.01$ ), IKK $\alpha$ plus IKK $\beta$ overexpression and single IKK $\gamma$ overexpression did not alter xenograft tumor formation ability in HOTAIR depleted cells groups (IKK $\alpha, \operatorname{IKK} \beta, \operatorname{IKK} \gamma, \operatorname{IKK} \alpha+\operatorname{IKK} \beta, \operatorname{IKK} \beta+\operatorname{IKK} \gamma$, $\operatorname{IKK} \alpha+\operatorname{IKK} \gamma, \operatorname{IKK} \alpha+\operatorname{IKK} \beta+\operatorname{IKK} \gamma)(\mathrm{P}>0.05)$ (Figure 9D). Taken together, these observations suggest that HOTAIR operates the oncogenic action of IKK $\alpha, \operatorname{IKK} \beta$, and IKK $\gamma$ in liver cancer stem cells.

\section{DISCUSSION}

Cancer stem cells (CSCs) are involved in tumorigenesis. The IKK is critical in cellular proliferation and in tumor-initiating [29]. However, the regulatory mechanism of IKKs has not been elucidated. To our knowledge, this is the first report demonstrating inflammatory related gene IKK $\alpha$, IKK $\beta$, and IKK $\gamma$ cooperate to determine liver cancer stem cells progression by altering telomere via heterochromatin protein 1-HOTAIR axis. As shown in Figure 10, we demonstrate that IKK $\alpha$ plus IKK $\beta$ promoted and IKK $\gamma$ inhibited liver cancer stem cell growth in vitro and in vivo. 


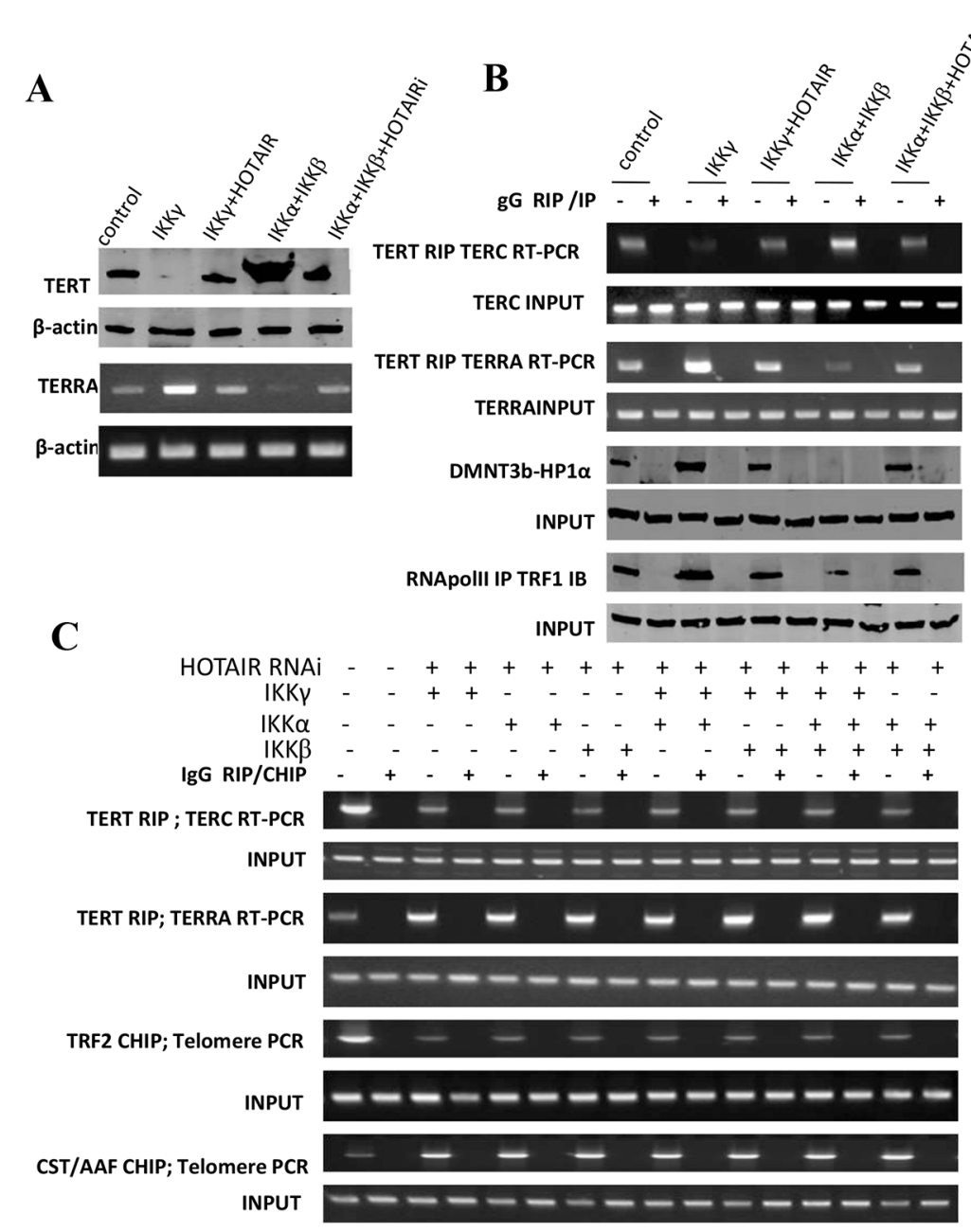

D

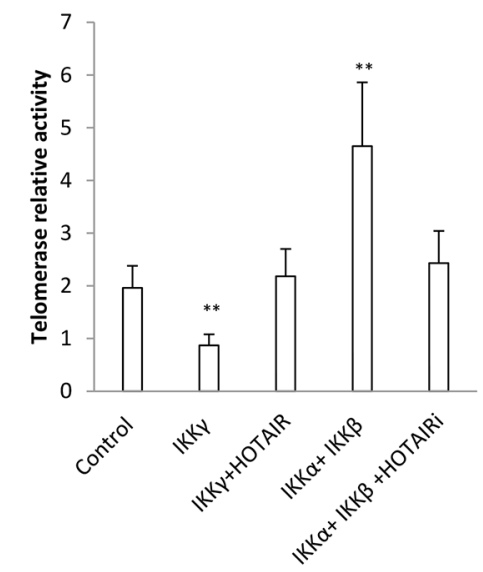

$\mathbf{E}$

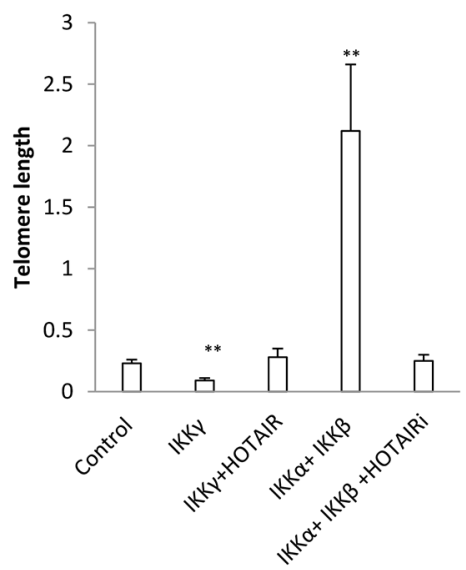

Figure 8: HOTAIR depletion blocks IKK $\alpha$, IKK $\boldsymbol{\beta}$, IKK $\boldsymbol{\gamma}$ function on telomere. A. (upper) Western blotting with anti-TERT in liver cancer stem cells transfected with pcDNA3.1, pcDNA3.1-IKK $\gamma$, pcDNA3.1-IKK $\gamma$ plus pCMV6-A-HOTAIR, pcDNA3.1-IKK $\alpha$ plus pcDNA3.1-IKK $\beta$, pcDNA3.1-IKK $\alpha$ plus pcDNA3.1-IKK $\beta$ plus pGFP--V-RS-HOTAIR, respectively. $\beta$-actin as internal control. (lower) RT-PCR with TERRA primers in liver cancer stem cells transfected with pcDNA3.1, pcDNA3.1-IKK $\gamma$, pcDNA3.1-IKK $\gamma$ plus pCMV6A-HOTAIR, pcDNA3.1-IKK $\alpha$ plus pcDNA3.1-IKK $\beta$, pcDNA3.1-IKK $\alpha$ plus pcDNA3.1-IKK $\beta$ plus pGFP--V-RS-HOTAIR, respectively. $\beta$-actin as internal control. B. (upper) RNA Immunoprecipitation (RIP) with anti-TERT followed by RT-PCR with TERC or TERRA promoter primers in liver cancer stem cells transfected with pcDNA3.1, pcDNA3.1-IKK $\gamma$, pcDNA3.1-IKK $\gamma$ plus pCMV6-A-HOTAIR, pcDNA3.1-IKK $\alpha$ plus pcDNA3.1-IKK $\beta$, pcDNA3.1-IKK $\alpha$ plus pcDNA3.1-IKK $\beta$ plus pGFP--V-RS-HOTAIR, respectively. IgG RIP as negative control. RT-PCR for TERC or TERRA as INPUT. (lower) Co-Immunoprecipitation (IP) with anti-RNA polII or anti-DNMT3b followed by western blotting with, anti-TRF1 or anti-HP1 $\alpha$ in liver cancer stem cells transfected with pcDNA3.1, pcDNA3.1-IKK $\gamma$, pcDNA3.1-IKK $\gamma$ plus pCMV6-A-HOTAIR, pcDNA3.1-IKK $\alpha$ plus pcDNA3.1-IKK $\beta$, pcDNA3.1-IKK $\alpha$ plus pcDNA3.1-IKK $\beta$ plus pGFP-V-RS-HOTAIR. IgG IP as negative control. Western blotting with anti-TRF1 or anti-HP1 $\alpha$ as INPUT. C. (upper) RNA Immunoprecipitation (RIP) with anti-TERT followed by RT-PCR with TERC and TERRA primers in HOTAIR depleted liver cancer stem cells transfected with pcDNA3.1-IKK $\alpha$, pcDNA3.1-IKK $\beta$, pcDNA3.1-IKK $\gamma$ respectively. IgG RIP as negative control. RT-PCR for TERC or TERRA as INPUT. (lower) Chromatin Immunoprecipitation (CHIP) with anti-TRF2 or antiCST/AAF followed by PCR with Telomere DNA primers in HOTAIR depleted liver cancer stem cells transfected with pcDNA3.1-IKK $\alpha$, pcDNA3.1-IKK $\beta$, pcDNA3.1-IKK $\gamma$ respectively. IgG CHIP as negative control. PCR for Ttelomere DNA promoter as INPUT. D. Telomerase activity assay with TRAP method primers in liver cancer stem cells transfected with pcDNA3.1, pcDNA3.1-IKK $\gamma$, pcDNA3.1-IKK $\gamma$ plus pCMV6-A-HOTAIR, pcDNA3.1-IKK $\alpha$ plus pcDNA3.1IKK $\beta$, pcDNA3.1-IKK $\alpha$ plus pcDNA3.1-IKK $\beta$ plus pGFP--V-RS-HOTAIR, respectively. Each value was presented as mean \pm standard error of the mean (SEM). **,P $<0.01$. E. The real-time PCR detection of telomere length primers in liver cancer stem cells transfected with pcDNA3.1, pcDNA3.1-IKK $\gamma$, pcDNA3.1-IKK $\gamma$ plus pCMV6-A-HOTAIR, pcDNA3.1-IKK $\alpha$ plus pcDNA3.1-IKK $\beta$, pcDNA3.1-IKK $\alpha$ plus pcDNA3.1-IKK $\beta$ plus pGFP--V-RS-HOTAIR, respectively. Each value was presented as mean \pm standard error of the mean (SEM). **, $\mathrm{P}<0.01$. 
Mechanistically, IKK $\alpha$ plus IKK $\beta$ enhanced and IKK $\gamma$ inhibited the interplay among HP1 $\alpha, \mathrm{HP} 1 \beta$ and HP1 $\gamma$ that competes for the interaction among HP1 $\alpha$, SUZ12, HEZ2. Therefore, IKK $\alpha$ plus IKK $\beta$ inhibited and IKK $\gamma$ enhanced the activity of H3K27 methyltransferase SUZ12 and EZH2, which methylates H3K27 immediately sites on HOTAIR promoter region. Therefore, IKK $\alpha$ plus IKK $\beta$ increased and IKK $\gamma$ decreased the TOTAIR expression. Strikingly, IKK $\alpha$ plus IKK $\beta$ decreases and IKK $\gamma$ increases the HP1 $\alpha$ interplays with DNA methyltransferase DNMT3b, which increases or decreases TERRA promoter DNA methylation. Thus IKK $\alpha$ plus IKK $\beta$ reduces and IKK $\gamma$ increases to recruit TRF1 and RNA polymerase II deposition and elongation on the TERRA promoter locus, which increases or decreases TREEA expression.
Furthermore, IKK $\alpha$ plus IKK $\beta$ decreases/increases and IKK $\gamma$ increases/decrease the interplay between TERT and TRRRA/between TERT and TREC. Ultimately, IKK $\alpha$ plus IKK $\beta$ increases and IKK $\gamma$ decreases the telomerase activity. On the other hand, at the telomere locus, IKK $\alpha$ plus IKK $\beta$ increases/drcreases and IKK $\gamma$ decreases/increases TRF2, POT1, pPOT1, Exo1, pExo1, SNM1B, pSNM1B/CST-AAF binding, which keep active telomere regulatory genes and poised for telomere length. Strikingly, HOTAIR is required for IKK $\alpha$ plus IKK $\beta$ and IKK $\gamma$ to control telomerase activity and telomere length. HOTAIR depletion blocks the function of IKK $\alpha$ plus IKK $\beta$, IKK $\gamma$ on telomere. These observations suggest that HOTAIR operates the action of IKK $\alpha$, IKK $\beta$, IKK $\gamma$ in liver cancer stem cells. This study provides a novel basis
A

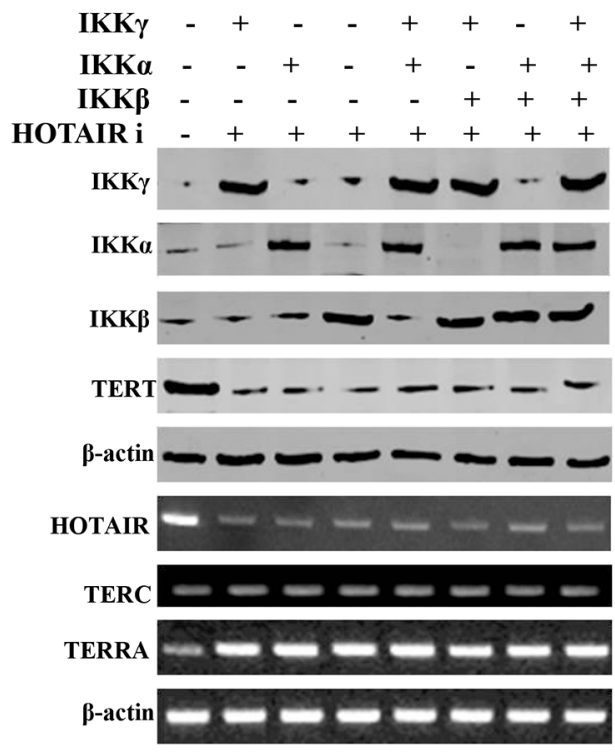

C

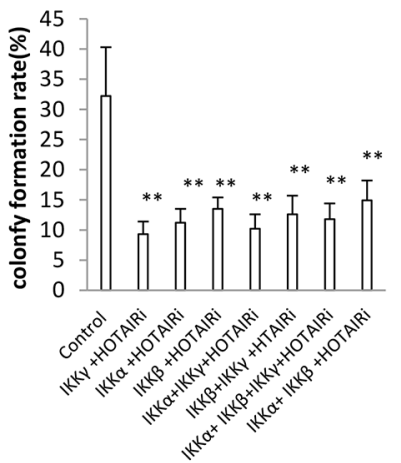

B

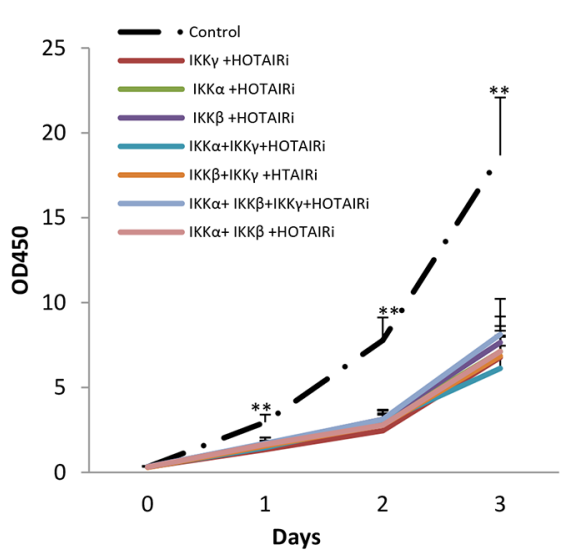

D

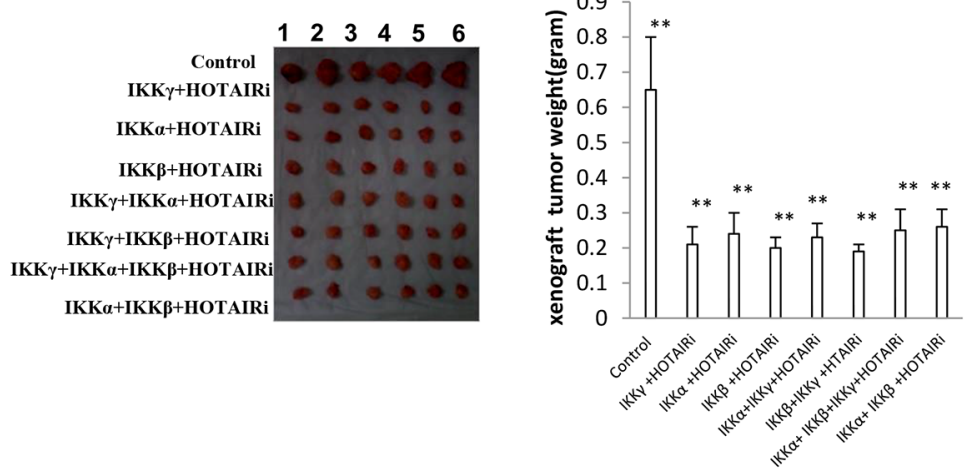

Figure 9: HOTAIR operates the oncogenic action of IKK $\boldsymbol{\alpha}$, IKK $\boldsymbol{\beta}$, IKK $\boldsymbol{\gamma}$. A. The Western blotting analysis of IKK $\alpha$, IKK $\beta$, IKK $\gamma$, TERT and RT-PCR analysis for HOTAIR, TERC, TERRA in HOTAIR depleted liver cancer stem cell lines transfected with pcDNA3.1-IKK $\alpha$, pcDNA3.1-IKK $\beta$, pcDNA3.1-IKK $\gamma$ respectively. $\beta$-actin as internal control. B. Cells growth assay using CCK8. Each value was presented as mean \pm standard error of the mean (SEM). Data are means of value from three independent experiments, bar \pm SEM. **, $\mathrm{P}<0.01 ; *, \mathrm{P}<0.05$. C. Cells soft agar colony formation assay. Each value was presented as mean \pm standard error of the mean (SEM). Data are means of value from three independent experiments, bar \pm SEM. ${ }^{* *}, \mathrm{P}<0.01 ;{ }^{*}, \mathrm{P}<0.05$. D. (left) The mice were stratified and the tumors were recovered. The photography of xenograft tumor in the eight groups. (right) The wet weight of each tumor was determined for each mouse. Each value was presented as mean \pm standard error of the mean $(\mathrm{SEM})$. bar $\pm \mathrm{SEM}$. ${ }^{* *}, \mathrm{P}<0.01 ;{ }^{*}, \mathrm{P}<0.05$. 
to elucidate the oncogenic action of IKK $\alpha, \operatorname{IKK} \beta$, IKK $\gamma$ and prompts that IKK $\alpha$, IKK $\beta$, IKK $\gamma$ cooperate to HOTAR to be used as a new therapeutic targets for liver cancer.

It is worth mentioning that IKK $\alpha$, IKK $\beta$, IKK $\gamma$ may play an important role in hepatocarcinogenesis. In this report, we focused mainly on the view how IKK $\alpha$, IKK $\beta$, IKK $\gamma$ function during liver cancer stem cells malignant growth. To this date, accumulating evidence indicates that IKK $\alpha$, IKK $\beta$, IKK $\gamma$ influence on cell proliferation. For examples, inhibition of IKK/NF- $\mathrm{BB}$ pathway controls stem cell proliferation [30]. IKK $\beta$ plays a role during intestinal tumorigenesis [31]. BRAF-induced tumorigenesis is dependent on IKK $\alpha$ [32]. IKK $\beta$ could regulates VEGF expression in ovarian cancer as an antiangiogenic target [33]. Our present findings are consistent with some reports.

It is worth noting that our findings in this study provide novel evidence for an active role of IKK $\alpha$ plus

A

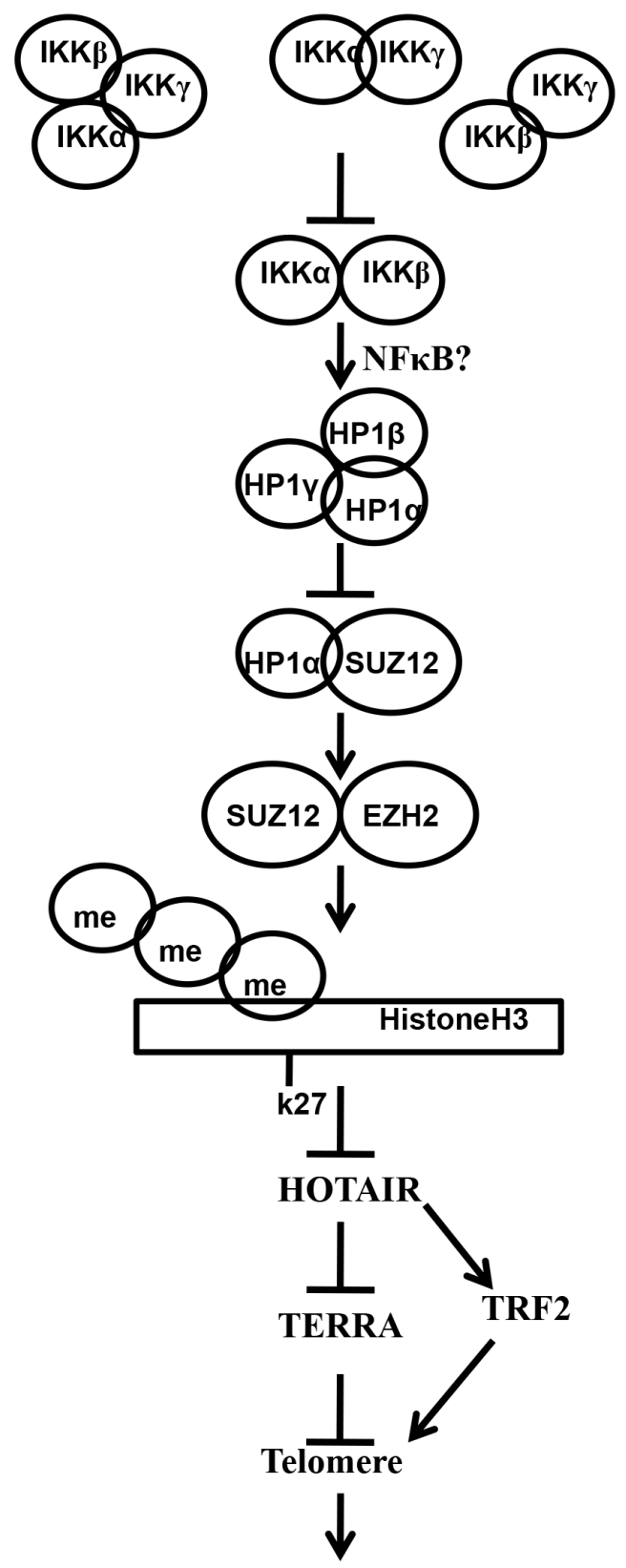

Liver cancer stem cells malignant transformation

Figure 10: The schematic diagram illustrates a model that that IKK $\alpha$ plus IKK $\beta$ promoted and IKK $\gamma$ inhibited liver cancer stem cell growth in vitro and in vivo. (Continued) 


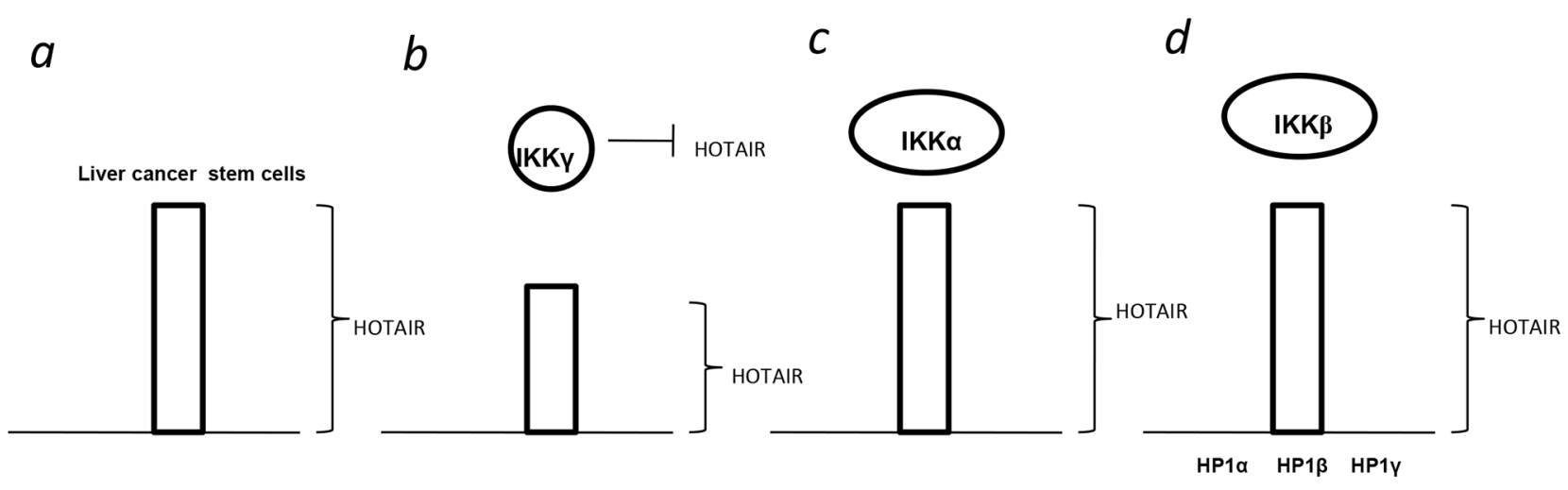

e

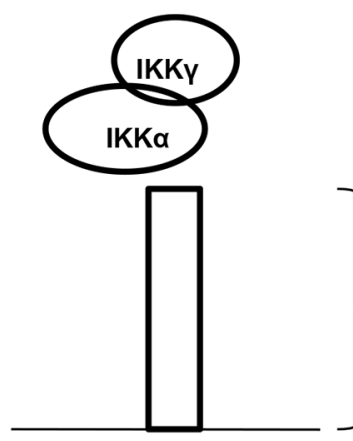

$f$

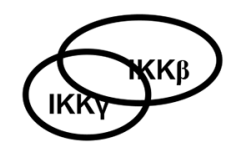

$g$

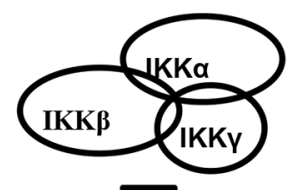

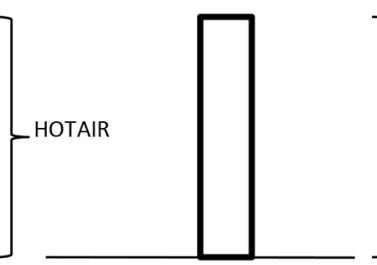

\} HOTAIR

$h$

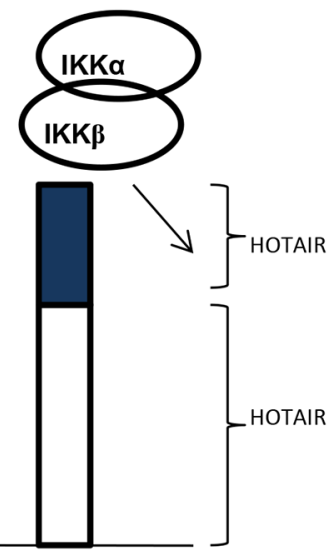

Figure 10: (Continued)The schematic diagram illustrates a model that that IKKa plus IKK $\beta$ promoted and IKK $\gamma$ inhibited liver cancer stem cell growth in vitro and in vivo. A. IKK $\alpha$ plus IKK $\beta$ enhanced and IKK $\gamma$ inhibited the interplay among HP $1 \alpha$, HP $1 \beta$ and HP $1 \gamma$ that competes for the interaction among HP1 $\alpha$, SUZ12, HEZ2. Therefore, IKK $\alpha$ plus IKK $\beta$ inhibited and IKK $\gamma$ enhanced the activity of H3K27 methyltransferase SUZ12 and EZH2, which methylates H3K27 immediately sites on HOTAIR promoter region. Therefore, IKK $\alpha$ plus IKK $\beta$ increased and IKK $\gamma$ decreased the TOTAIR expression. Strikingly, IKK $\alpha$ plus IKK $\beta$ decreases and IKK $\gamma$ increases the HP1 $\alpha$ interplays with DNA methyltransferase DNMT3b, which increases or decreases TERRA promoter DNA methylation. So IKK $\alpha$ plus IKK $\beta$ reduces and IKK $\gamma$ increases to recruit TRF1 and RNA polymerase II deposition and elongation on the TERRA promoter locus, which increases or decreases TREEA expression. Further on, IKK $\alpha$ plus IKK $\beta$ decreases/increases and IKK $\gamma$ increases/ decrease the interplay between TERT and TRRRA/between TERT and TREC. Ultimately, IKK $\alpha$ plus IKK $\beta$ increases and IKK $\gamma$ decreases the telomerase activity. On the other hand, at the telomere locus, IKK $\alpha$ plus IKK $\beta$ increases/drcreases and IKK $\gamma$ decreases/increases TRF2, POT1, pPOT1, Exo1, pExo1, SNM1B, pSNM1B/CST-AAF binding, which keep active telomere regulatory genes and poised for telomere length. B. HOTAIR is required for IKK $\alpha$ plus IKK $\beta$ and IKK $\gamma$ to control telomerase activity and telomere length. HOTAIR depletion blocks the function of IKK $\alpha$ plusIKK $\beta$, IKK $\gamma$ on telomere.

IKK $\beta$ promotion or IKK $\gamma$ inhibition of liver cancer stem cell growth. Herein, the involvement of promotion or inhibition of liver cancer stem cells growth based on IKK $\alpha$, IKK $\beta$, IKK $\gamma$ is supported by results from two parallel sets of experiments: (1) IKK $\alpha$ plus IKK $\beta$ promoted and IKK $\gamma$ inhibited liver cancer stem cell growth in vitro; (2) IKK $\alpha$ plus IKK $\beta$ promoted and IKK $\gamma$ inhibited liver cancer stem cell growth in vivo.

Strikingly, our observations suggest that IKK $\alpha$ plus IKK $\beta$ increased and IKK $\gamma$ inhibited HOTAIR expression dependent on tri-methylation of Histone $\mathrm{H} 3$ on the twenty-seven lysine. This assertion is based on several observations in IKK $\alpha$ plus IKK $\beta$ or IKK $\gamma$ overexpressed liver cancer stem cells: (1) IKK $\alpha$ plus IKK $\beta$ enhanced and IKK $\gamma$ inhibited the interplay among HP1 $\alpha$, HP $1 \beta$ and HP1 $\gamma$ that competes for the interaction among HP1 $\alpha$, SUZ12, HEZ2. (2) IKK $\alpha$ plus IKK $\beta$ inhibited and IKK $\gamma$ increased methylation of histoneH3 on lysine 27 dependent on the tri-complex of HP1. (3) IKK $\alpha$ plus IKK $\beta$ increased and IKK $\gamma$ decreased the H3K27Ac and NF- 
$\kappa \mathrm{B}$ through $\mathrm{H} 3 \mathrm{~K} 27 \mathrm{me}$. (4) IKK $\alpha$ plus IKK $\beta$ increased and IKK $\gamma$ decreased HOTAIR expression dependent on $\mathrm{H} 3 \mathrm{~K} 27 \mathrm{me}$. Researches indicated heterochromatin causes epigenetic repression that control gene expression and function [34]. HP1 $\alpha$ is an essential protein critical for heterochromatin assembly and regulation [35]. Strikingly, HP1 promotes tumor suppressor BRCA1 functions during the DNA damage response [36]. The trimethylation of histone $\mathrm{H} 3$ lysine 27 (H3K27me3) contributes to gene repression [37]. NF- $\mathrm{kB}$ is involved in inflammation and tumor growth [38].

On the other hand, we find that IKK $\alpha, \operatorname{IKK} \beta$, and IKK $\gamma$ control telomerase activity and telomere length. The stability of telomeres depends upon TRF2, which prevents inappropriate repair [39]. Upon telomere shortening or telomere uncapping induced by loss of TRF2, telomeres elicit a DNA-damage response [40]. Our previous study shows CUDR promotes liver cancer stem cell growth through upregulating TERT [41]. In addition, telomeres are protected from hyper-resection through the repression of the ATM and ATR kinases by TRF2 and TPP1-bound POT1a/b, respectively [42]. Shelterin can protect chromosome ends as a TRF2-tethered TIN2/TPP1/POT1 complex [43]. This assertion is based on several observations in TLR4 overexpression or knockdown liver cancer stem cells: (1) When IKK $\alpha$ and IKK $\beta$ were co-overexpressed, the telomerase activity and telomere length were significantly increased. (2) Conversely, when only IKK $\gamma$ was overexpressed, the telomerase activity and telomere length were significantly decreased. (3) IKK $\alpha$ plus IKK $\beta$ decreased and IKK $\gamma$ increased the HP1 $\alpha$ interplay with DNA methyltransferase DNMT3b, which increased or decreased TERRA promoter DNA methylation. (2) IKK $\alpha$ plus IKK $\beta$ reduced and IKK $\gamma$ increased to recruit TRF1 and RNA polymerase II deposition and elongation on the TERRA promoter locus, which increased or decreased TREEA expression. (3) IKK $\alpha$ plus IKK $\beta$ decreases/ increases and IKK $\gamma$ increases/decrease the interplay between TERT and TRRRA/between TERT and TREC. (4) IKK $\alpha$ plus IKK $\beta$ increases/drcreases and IKK $\gamma$ decreases/increases TRF2, POT1, pPOT1, Exo1, pExo1, SNM1B, pSNM1B/CST-AAF binding, which keep active telomere regulatory genes and poised for telomere length.

Significantly, HOTAIR is required for IKK $\alpha$ plus $\operatorname{IKK} \beta$ and IKK $\gamma$ to control telomerase activity, telomere length and tumorigenesis. HOTAIR is associated with a variety of human cancers, such as breast, liver and endometrial carcinoma [44]. HOTAIR induced colony formation and orthotopic tumor growth [45]. HOTAIR directly decreased WIF-1 expression by promoting its histone H3K27 methylation and then activated the Wnt/ $\beta$ catenin signaling pathway [46]. Furthermore, HOTAIR promotes proliferation of ovarian cancer cells through regulating PIK3R3 [47]. Herein, the involvement of promotion or inhibition of telomere length or telomerase activity based on IKK $\alpha$, IKK $\beta$, IKK $\gamma$ is supported by results from three parallel sets of experiments: (1) HOTAIR depletion abolished the function of IKK $\alpha$ plus IKK $\beta$, IKK $\gamma$ on telomere length. (2) HOTAIR depletion abolished the function of IKK $\alpha$ plus IKK $\beta$, IKK $\gamma$ on telomerase. (2) HOTAIR depletion abrogated IKK $\alpha$ plus IKK $\beta$ oncogenic function.

Especially, our results showed IKK $\alpha$ plus IKK $\beta$ enhanced the interplay among HP1 $\alpha$, HP1 $\beta$ and HP $1 \gamma$ by an unknown mechanism, and then inhibited the activity of H3K27 methyltransferase SUZ12 and EZH2 and increased the HOTAIR expression. However, single IKK $\alpha$ or IKK $\beta$ overexpression could not alter HOTAIR expression. Because of excessive HOTAIR, IKK $\alpha$ plus IKK $\beta$ increases the interplay between TERT and TREC, the telomerase activity and telomere length. However, single IKK $\alpha$ or IKK $\beta$ overexpression could not alter the telomerase activity, increases telomere length. Moreover, because of the increase of telomerase activity and telomere length, IKK $\alpha$ plus IKK $\beta$ simultaneous overexpression significantly increased liver cancer stem cells's growth, while single IKK $\alpha$ or IKK $\beta$ overexpression could not promote liver cancer stem cells's growth.

In addition, our results showed that HOTAIR depletion blocks IKK $\alpha$ plus IKK $\beta$, IKK $\gamma$ function on telomere. It suggest HOTAIR is required for IKK $\alpha$ plus IKK $\beta$ and IKK $\gamma$ to control telomerase activity and telomere length. In this study, we found IKK $\alpha$ plus IKK $\beta$ enhanced and HP $1 \gamma$ decreased the interplay among HP $1 \alpha$, HP $1 \beta$ and HP $1 \gamma$ by an unknown mechanism, and then IKK $\alpha$ plus IKK $\beta$ inhibited and HP1 $\gamma$ enhanced the activity of H3K27 methyltransferase SUZ12 and EZH2. Ultimately, IKK $\alpha$ plus IKK $\beta$ increased and HP1 $\gamma$ decreased the HOTAIR expression. Because of HOTAIR, IKK $\alpha$ plus IKK $\beta$ increases and HP $1 \gamma$ decreased the interplay between TERT and TREC, the telomerase activity and telomere length. IKK is also a crucial protein kinase that activates NF- $\mathrm{\kappa B}$ translocating from cytoplasm to nucleus for DNA binding. Especially, IKK phosphorylates NF- $\mathrm{\kappa B}$ to modulate its promoter specificity and promote genes expression. NF- $\mathrm{\kappa B}$ could regulates and controls telomere related genes. Although IKK could regulate NF- $\mathrm{\kappa B}$ and HOTAIR, both abnormal $\mathrm{NF}-\kappa \mathrm{B}$ and HOTAIR could alter telomeres through different pathways.

We should explore the function of IKK $\alpha$ plus IKK $\beta$, IKK $\gamma$ in liver cancer stem cells. For example, what causes strong oncogenic action of IKK $\alpha$ plus IKK $\beta$ and triggers IKK $\gamma$ 's actions? How does IKK $\alpha$ plus IKK $\beta$, IKK $\gamma$ cooperates with HOTAIR? Does IKK $\alpha$ plus IKK $\beta$, IKK $\gamma$ regulates a series of molecular events liver stem cells malignant growth? Answering these questions will help understand the mechanism about liver stem cell malignant differentiation. In summary, our present data indicated that IKK $\alpha$ plus IKK $\beta$, and IKK $\gamma$ promotes/inhibits liver cancer 
stem cells malignant progression through altering telomere length and telomerase activity dependent on HOTAIR, with clinic implications. These observations provide insight into a novel link between IKK $\alpha$, IKK $\beta$, IKK $\gamma$ and liver cancer stem malignant transformation.

\section{MATERIALS AND METHODS}

\section{Human liver cancer stem cell line (hLCSC) sorting}

CD133/CD44/CD24/EpCAM MicroBead Kits were purchased from Miltenyi technic (Boston, USA) and MACS ${ }^{\circledR}$ Technology operation according to and the operation according to the manufacturer. In brief, centrifuge cell suspension at $300 \times \mathrm{g}$ for 10 minutes and. Resuspend cell pellet in $300 \mu \mathrm{L}$ of buffer per $10^{8}$ total cells after aspirating supernatant completely. Add 100 $\mu \mathrm{L}$ of FcR Blocking Reagent per $10^{8}$ total cells and 100 $\mu \mathrm{L}$ of CD133/CD44/CD24/EpCAM MicroBeads per $10^{8}$ total cells. Mix well and incubate for 30 minutes in the refrigerator $\left(2-8^{\circ} \mathrm{C}\right)$. Wash cells by adding $1-2 \mathrm{~mL}$ of buffer per $10^{8}$ cells and centrifuge at $300 \times \mathrm{g}$ for 10 minutes. Resuspend up to $10^{8}$ cells in $500 \mu \mathrm{L}$ of buffer. Choose an appropriate MACS Column and MACS Separator according to the number of total cells and the number of CD133+/CD44+/CD24+/EpCAM+ cells.

\section{Cell lines and plasmids}

Liver cancer stem cell lines were maintained in Dulbecco's modified Eagle medium (Gibco BRL Life Technologies) supplemented with $10 \%$ heat-inactivated fetal bovine serum (Gibco BRL Life Technologies) in a humidified atmosphere of $5 \% \mathrm{CO}_{2}$ incubator at $37^{\circ} \mathrm{C}$. pCMV6-A-GFP, pGFP-V-RS were purchased from Origene (Rockville, MD, USA). pcDNA3.1-IKK $\alpha$, pcDNA3.1-IKK $\beta$, pcDNA3.1-IKK $\gamma$ were purchase from Addgene (Cambridge MA, USA). pCMV6-A-GFPHOTAIR, pGFP-V-RS-HOTAIR, pGFP-V-RS-HP1 $\alpha$, pGFP-V-RS--HP1 $\beta$, pGFP-V-RS--HP1 $\gamma$, pGL4-HOTAIR/ promoter were prepared by ourselves.

\section{Cell transfection and stable cell lines cell transfection and stable cell lines}

Cells were transfected with DNA plasmids using transfast transfection reagent lipofectamine ${ }^{\mathrm{R}} 2000$ (Invitrogen) according to manufacturer's instructions.

\section{RT-PCR}

Total RNA was purified using Trizol (Invitrogen) according to manufacturer's instructions. cDNA was prepared by using oligonucleotide $(\mathrm{dT})_{17-18}$, random primers, and a SuperScript First-Strand Synthesis System (Invitrogen). PCR analysis was performed under the specical conditions. $\beta$-actin was used as an internal control.

\section{Western blotting}

The logarithmically growing cells were washed twice with ice-cold phosphate-buffered saline (PBS, Hyclone) and lysed in a RIPA lysis buffer. Cells lysates were centrifuged at $12,000 \mathrm{~g}$ for 20 minutes at $4^{\circ} \mathrm{C}$ after sonication on ice, and the supernatant were separated. After being boiled for 5-10 minutes in the presence of 2-mercaptoethanol, samples containing cells proteins were separated on a $10 \%$ sodium dodecyl sulfatepolyacrylamide gel electrophoresis (SDS-PAGE) and transferred onto a nitrocellulose membranes (Invitrogen, Carlsbad, CA, USA). Then blocked in $10 \%$ dry milkTBST (20mM Tris-HCl [PH 7.6], $127 \mathrm{mM} \mathrm{NaCl}, 0.1 \%$ Tween 20) for $1 \mathrm{~h}$ at $37^{\circ} \mathrm{C}$. Following three washes in Tris$\mathrm{HCl} \mathrm{pH} 7.5$ with $0.1 \%$ Tween 20 , the blots were incubated with $0.2 \mu \mathrm{g} / \mathrm{ml}$ of antibody (appropriate dilution) overnight at $4^{\circ} \mathrm{C}$. Following three washes, membranes were then incubated with secondary antibody for $60 \mathrm{~min}$ at $37^{\circ} \mathrm{C}$ or $4^{\circ} \mathrm{C}$ overnight in TBST. Signals were visualized by ODYSSEY infrared imaging system (LI-COR, Lincoln, Nebraska USA). IRDye 680LT secondary antibodies were purchased from LI-COR scientific company.

\section{Co-immunoprecipitation (IP)}

Cells were lysed in $1 \mathrm{ml}$ of the whole-cell extract buffer A $(50 \mathrm{mM}$ pH7.6 Tris- $\mathrm{HCl}, 150 \mathrm{mMNaCl}$, $1 \% \mathrm{NP} 40, \quad 0.1 \mathrm{mMEDTA}, 1.0 \mathrm{mM} \quad$ DTT,0.2mMPMSF, $0.1 \mathrm{mM}$ Pepstatine, $0.1 \mathrm{mM}$ Leupeptine, $0.1 \mathrm{mM}$ Aproine). Five-hundred-microliter cell lysates was used in immunoprecipitation with antibody. In brief, protein was pre-cleared with $30 \mu \mathrm{l}$ protein G/A-plus agarose beads (Santa Cruz, Biotechnology, Inc. CA) for 1 hour at $4^{\circ} \mathrm{C}$ and the supernatant was obtained after centrifugation $(5,000 \mathrm{rpm})$ at $4^{\circ} \mathrm{C}$. Precleared homogenates (supernatant) were incubated with $2 \mu \mathrm{g}$ of antibody and/ or normal mouse/rabbit IgG by rotation for 4 hours at $4^{\circ} \mathrm{C}$, and then the immunoprecipitates were incubated with $30 \mu \mathrm{l}$ protein $\mathrm{G} / \mathrm{A}$-plus agarose beads by rotation overnight at $4^{\circ} \mathrm{C}$, and then centrifuged at $5000 \mathrm{rpm}$ for $5 \mathrm{~min}$ at $4^{\circ} \mathrm{C}$. The precipitates were washed five times $\times 10 \mathrm{~min}$ with beads wash solution $(50 \mathrm{mM} \mathrm{pH} 7.6$ TrisCl,150mMNaCl, $0.1 \% \mathrm{NP}-40,1 \mathrm{mM}$ EDTA) and then resuspended in $60 \mu 12 \times$ SDS-PAGE sample loading buffer to incubate for $10 \mathrm{~min}$ at $100^{\circ} \mathrm{C}$. Then Western blot was performed with a another related antibody indicated in Western blotting.

\section{RNA immunoprecipitation (RIP)}

Cells were lysed $\left(15 \mathrm{~min}, 4^{\circ} \mathrm{C}\right)$ in $100 \mathrm{mM} \mathrm{KCl}$, $5 \mathrm{mM} \mathrm{MgCl}, 10 \mathrm{mM}$ HEPES [pH 7.0], 0.5\% NP40, 1 $\mathrm{mM}$ DTT, 100 units/ml RNase OUT (Invitrogen), $400 \mu \mathrm{M}$ 
vanadyl-ribonucleoside complex and protease inhibitors (Roche). The lysates were incubated with specific antibody or normal mouse/rabbit IgG overnight at $4^{\circ} \mathrm{C}$, followed that the lysates were incubated with protein $\mathrm{A} / \mathrm{G}$ plus agarose beads (Santa Cruz, Biotechnology, Inc. CA) 4 hours at $4^{\circ} \mathrm{C}$. Then the beads were subsequently washed four times with $50 \mathrm{mM}$ Tris- $\mathrm{HCl}(\mathrm{pH} 7.0), 150 \mathrm{mM} \mathrm{NaCl}$, $1 \mathrm{mM} \mathrm{MgCl}_{2}$, and $0.05 \% \mathrm{NP}-40$, and twice after addition of $1 \mathrm{M}$ Urea. RNA is isolated from the Immunoprecipitates (IPs) and RT-PCR is performed.

\section{DNA pull down}

Cells were lysed by sonication in HKMG buffer (10 mM HEPES, PH7.9, $100 \mathrm{mM} \mathrm{KCl,} 5 \mathrm{mM} \mathrm{MgCl}$, $100 \%$ glycerol, $1 \mathrm{mM}$ DTT, and $0.5 \%$ NP40) containing protease and phosphatase inhibitors for the preparation of nuclear exact. Equal amount of cell nuclear extracts were precleared with Streptavidin-agarose Resin (Thermo) for 1 hours, and then were incubated with $1 \mu \mathrm{g}$ biotinylated double-stranded-oligonucleotides and together with $10 \mu \mathrm{g}$ poly $(\mathrm{dI}-\mathrm{dC})$ at $4{ }^{\circ} \mathrm{C}$ for 24 hours. DNA-bound proteins were collected with the incubation with streptavidinagarose Resin for 1 hour with gently shaking to prevent precipitation in solution. Following 5 washings of the resin bound complex with $0.5-1.0 \mathrm{ml}$ of binding buffer, the samples were boiled and subjected to SDS-PAGE and Western blot analysis.

\section{Chromatin immunoprecipitation (CHIP) assay}

Cells were cross-linked with $1 \%(\mathrm{v} / \mathrm{v})$ formaldehyde (Sigma) for $10 \mathrm{~min}$ at room temperature and stopped with $125 \mathrm{~mm}$ glycine for $5 \mathrm{~min}$. Crossed-linked cells were washed with phosphate-buffered saline, resuspended in lysis buffer, and sonicated for 8-10 $\mathrm{min}$ in a SONICS VibraCell to generate DNA fragments with an average size of $500 \mathrm{bp}$ or so. Chromatin extracts were diluted 5-fold with dilution buffer, pre-cleared with Protein-A/GSepharose beads, and immunoprecipitated with specific antibody on Protein-A/G-Sepharose beads. After washing, elution and de-cross-linking, the ChIP DNA was detected by PCR.

\section{Super-EMSA (Gel-shift)}

Cells were washed and scraped in ice-cold PBS to prepare nuclei for electrophoretic gel mobility shift assay with the use of the gel shift assay system modified according to the manufacturer's instructions (Promega).

\section{Quantitative telomerase detection}

The telomerase activity was measured by using Quantitative Telomerase Detection Kit (MT3010) according to manufacturer's instructions (US Biomax, Inc).

\section{Telomere length assay}

Telomere length assay using Telo TAGGG PCR ELISApuls kit according to manufacturer's instructions (Roche). A standard curve is established by dilution of known quantities of a synthesised 84 mer oligonucleotide containing only TTAGGG repeats.

\section{Methylation analysis}

mthylated DNA Immunoprecipitation (MeDIP)-Dot blot-western blotting with anti-5-Methylcytosine (5-mC) and ethylation analysis by MspI plus BamHI digestion.

\section{Cells proliferation CCK8 assay}

Cells were synchronized in G0 phase by serum deprivation and then released from growth arrest by reexposure to serum, and then cells were grown in complete medium for assay. The cell proliferation reagent $\mathrm{CCK} 8$ is purchased from Roch and the operation according to the manufacturer instruction.

\section{Soft agar colony formation capacity assay}

$2 \times 10^{2}$ cells were plated on a 6 well plate containing $0.5 \%$ (lower) and $0.35 \%$ (upper) double layer soft-agar. The 6 well plates were incubated at $37^{\circ} \mathrm{C}$ in humidified incubator for 14 days. The cells were fed 1-2 times per week with cell culture media (DMEM). Soft-agar colonies on the 6 well plates were stained with $0.5 \mathrm{ml}$ of $0.05 \%$ Crystal Violet for more than 1 hour and the colonies were counted.

\section{BrdU staining}

$70-80 \%$ confluent cells were cultured for 24 hour before treatment with $10 \mu \mathrm{l}$ BrdU (Roche) for 4 hours. Immunofluorescent staining with an anti-BrdU antibody was performed according to the manufacturer's instructions (Becton Dickinson). BrdU positive cells from ten random chosen fields of at least three independent samples were counted.

\section{Xenograft transplantation in vivo}

The Four-weeks athymic Balb/C mouse was injected the liver cancer cells at the armpit area subcutaneously. The mice were observed over 4 weeks, and then sacrificed to recover the tumors. The wet weight of each tumor was determined for each mouse. A portion of each tumor was fixed in 4\% paraformaldehyde and embedded in paraffin for histological hematoxylineosin (HE) staining. The use of mice for this work was reviewed and approved by the institutional animal care and use committee in accordance with China national institutes of health guidelines. 


\section{Statistical analysis}

The significant differences between mean values obtained from at least three independent experiments. Each value was presented as mean \pm standard error of the mean (SEM) unless otherwise noted, with a minimum of three replicates. Student's t-test was used for comparisons, with $\mathrm{P}<0.05$ considered significant.

\section{ACKNOWLEDGMENTS}

This study was supported by grants from Science and Technology Commission of Shanghai Municipality (No13JC1405500-13JC1405501), National Natural Science Fundation of China (NCSF No.81272291) and National Natural Science Fundation of China (NCSF No.81572773).

\section{CONFLICTS OF INTEREST}

The authors disclose no conflicts.

\section{REFERENCES}

1. Huang JJ, Chu HX, Jiang ZY, Zhang XJ, Sun HP, You QD. Recent advances in the structure-based and ligand-based design of IKK $\beta$ inhibitors as anti-inflammation and anticancer agents. Curr Med Chem. 2014; 21:3893-91.

2. Shukla S, Kanwal R, Shankar E, Datt M, Chance MR, Fu P, MacLennan GT, Gupta S. Apigenin blocks IKK $\alpha$ activation and suppresses prostate cancer progression. Oncotarget. 2015; 6:31216-32. doi: 10.18632/oncotarget.5157.

3. Li T, Wong VK, Jiang ZH, Jiang SP, Liu Y, Wang TY, Yao XJ, Su XH, Yan FG, Liu J, Leung EL, Yi XQ, Wong YF, et al. Mutation of cysteine 46 in IKK-beta increases inflammatory responses. Oncotarget. 2015; 6:31805-19. doi: 10.18632/oncotarget.5567.

4. Singha B, Gatla HR, Phyo S, Patel A, Chen ZS, Vancurova I. IKK inhibition increases bortezomib effectiveness in ovarian cancer. Oncotarget. 2015; 6:26347-58. doi: 10.18632/ oncotarget.4613.

5. Li Z, Yang Z, Lapidus RG, Liu X, Cullen KJ, Dan HC. IKK phosphorylation of NF- $\mathrm{KB}$ at serine 536 contributes to acquired cisplatin resistance in head and neck squamous cell cancer. Am J Cancer Res. 2015; 5:3098-110.

6. Authier H, Billot K, Derudder E, Bordereaux D, Rivière P, Rodrigues-Ferreira S, Nahmias C, Baud V. IKK phosphorylates RelB to modulate its promoter specificity and promote fibroblast migration downstream of TNF receptors. Proc Natl Acad Sci U S A. 2014; 111:14794-9.

7. Kim SW, Schifano M, Oleksyn D, Jordan CT, Ryan D, Insel R, Zhao J, Chen L. Protein kinase C-associated kinase regulates NF- $\kappa \mathrm{B}$ activation through inducing IKK activation. Int J Oncol. 2014; 45:1707-14.

8. Vad-Nielsen J, Jakobsen KR, Daugaard TF, Thomsen R, Brügmann A, Sørensen BS, Nielsen AL. Regulatory dissection of the CBX5 and hnRNPA1 bi-directional promoter in human breast cancer cells reveals novel transcript variants differentially associated with HP1 $\alpha$ down-regulation in metastatic cells. BMC Cancer. 2016; 16:32.

9. Mishima Y, Jayasinghe CD, Lu K, Otani J, Shirakawa M, Kawakami T, Kimura H, Hojo H, Carlton P, Tajima S, Suetake I. Nucleosome compaction facilitates HP1 $\gamma$ binding to methylated H3K9. Nucleic Acids Res. 2015; 43:10200-12.

10. Kataoka K, Mochizuki K. Phosphorylation of an HP1-like Protein Regulates Heterochromatin Body Assembly for DNA Elimination. Dev Cell. 2015; 35:775-88.

11. Vad-Nielsen J, Nielsen AL. Beyond the histone tale: HP1 $\alpha$ deregulation in breast cancer epigenetics. Cancer Biol Ther. 2015; 16:189-200.

12. Xing Y, Li WX. Heterochromatin components in germline stem cell maintenance. Sci Rep. 2015; 5:17463.

13. Jamieson K, Wiles ET, McNaught KJ, Sidoli S, Leggett N, Shao Y, Garcia BA, Selker EU. Loss of HP1 causes depletion of H3K27me3 from facultative heterochromatin and gain of $\mathrm{H} 3 \mathrm{~K} 27 \mathrm{me} 2$ at constitutive heterochromatin. Genome Res. 2016; 26:97-107.

14. Yearim A, Gelfman S, Shayevitch R, Melcer S, Glaich O, Mallm JP, Nissim-Rafinia M, Cohen AH, Rippe K, Meshorer E, Ast G. HP1 is involved in regulating the global impact of DNA methylation on alternative splicing. Cell Rep. 2015; 10:1122-34.

15. Ding C, Cheng S, Yang Z, Lv Z, Xiao H, Du C, Peng C, Xie $\mathrm{H}$, Zhou L, Wu J, Zheng S. Long non-coding RNA HOTAIR promotes cell migration and invasion via down-regulation of RNA binding motif protein 38 in hepatocellular carcinoma cells. Int J Mol Sci. 2014; 15:4060-76.

16. Wu L, Murat $\mathrm{P}$, Matak-Vinkovic D, Murrell A, Balasubramanian S. Binding interactions between long noncoding RNA HOTAIR and PRC2.proteins. Biochemistry. 2013; 52:9519-27.

17. Pádua Alves C, Fonseca AS, Muys BR, de Barros E, Lima Bueno R, Bürger MC, de Souza JE, Valente V, Zago MA, Silva WA Jr. Brief report: The lincRNA Hotair is required for epithelial-to-mesenchymal transition and stemness maintenance of cancer cell lines. Stem Cells. 2013; 31:2827-32.

18. Gupta RA, Shah N, Wang KC, Kim J, Horlings HM, Wong DJ, Tsai MC, Hung T, Argani P, Rinn JL, Wang Y, Brzoska P, Kong B, Li R, West RB, van de Vijver MJ, Sukumar S, Chang HY. Long non-coding RNA HOTAIR reprograms chromatin state to promote cancer metastasis. Nature. 2010; 464:1071-6.

19. Jiao L, Liu X. Structural basis of histone H3K27 trimethylation by an active polycomb repressive complex 2. Science. 2015; 350:aac4383.

20. Conway E, Healy E, Bracken AP. PRC2 mediated H3K27 methylations in cellular identity and cancer. Curr Opin Cell Biol. 2015; 37:42-8. 
21. Tianming Li, Qidi Zheng, Jiahui An, Mengying Wu, Haiyan Li, Xin Gui, Hu Pu and Dongdong Lu. SET1A Cooperates With CUDR to Promote Liver Cancer Growth and Hepatocyte-like Stem Cell Malignant Transformation Epigenetically. Mol Ther 2016; 24:261-275.

22. Nera B, Huang HS, Lai T, Xu L. Elevated levels of TRF2 induce telomeric ultrafine anaphase bridges and rapid telomere deletions. Nat Commun. 2015; 6:10132.

23. Maida Y, Yasukawa M, Furuuchi M, Lassmann T, Possemato R, Okamoto N, Kasim V, Hayashizaki Y, Hahn WC, Masutomi K. An RNA-dependent RNA polymerase formed by TERT and the RMRP RNA. Nature. 2009 0; 461:230-5.

24. Biffi G, Tannahill D, Balasubramanian S. An intramolecular G-quadruplex structure is required for binding of telomeric repeat-containing RNA to the telomeric protein TRF2.J Am Chem Soc. 2012; 134:11974-6.

25. Wang C, Zhao L, Lu S. Role of TERRA in the regulation of telomere length. Int J Biol Sci. 2015; 11:316-23.

26. Pfeiffer V, Lingner J. TERRA promotes telomere shortening through exonuclease 1-mediated resection of chromosome ends. PLoS Genet. 2012; 8:e1002747.

27. Mason JM, Das I, Arlt M, Patel N, Kraftson S, Glover TW, Sekiguchi JM. The SNM1B/APOLLO DNA nuclease functions in resolution of replication stress and maintenance of common fragile site stability.Hum Mol Genet. 2013; 22:4901-13.

28. Wu P, Takai H, de Lange T. Telomeric 3' overhangs derive from resection by Exo1 and Apollo and fill-in by POT1bassociated CST. Cell. 2012; 150:39-52.

29. Bradford JW, Baldwin AS. IKK/nuclear factor-kappaB and oncogenesis: roles in tumor-initiating cells and in the tumor microenvironment.Adv Cancer Res. 2014; 121:125-45.

30. Lu A, Proto JD, Guo L, Tang Y, Lavasani M, Tilstra JS, Niedernhofer LJ, Wang B, Guttridge DC, Robbins PD, Huard J. NF- $\kappa$ B negatively impacts the myogenic potential of muscle-derived stem cells.Mol Ther. 2012; 20:661-8.

31. Pallangyo CK, Ziegler PK, Greten FR. IKK $\beta$ acts as a tumor suppressor in cancer-associated fibroblasts during intestinal tumorigenesis. J Exp Med. 2015; 212:2253-66.

32. Margalef P, Colomer C, Villanueva A, Montagut C, Iglesias M, Bellosillo B, Salazar R, Martínez-Iniesta M, Bigas A, Espinosa L. BRAF-induced tumorigenesis is IKK $\alpha$ dependent but NF-кB-independent.Sci Signal. 2015; 8:ra38.

33. Kinose Y, Sawada K, Makino H, Ogura T, Mizuno T, Suzuki N, Fujikawa T, Morii E, Nakamura K, Sawada I, Toda A, Hashimoto K, Isobe A, et al. IKK $\beta$ Regulates VEGF Expression and Is a Potential Therapeutic Target for Ovarian Cancer as an Antiangiogenic Treatment.Mol Cancer Ther. 2015; 14:909-19.

34. Aygün O, Mehta S, Grewal SI. HDAC-mediated suppression of histone turnover promotes epigenetic stability of heterochromatin.Nat Struct Mol Biol. 2013; 20:547-54.
35. Figueiredo ML, Philip P, Stenberg P, Larsson J. HP1a recruitment to promoters is independent of $\mathrm{H} 3 \mathrm{~K} 9$ methylation in Drosophila melanogaster.PLoS Genet. 2012; 8:e1003061.

36. Lee YH, Kuo CY, Stark JM, Shih HM, Ann DK. HP1 promotes tumor suppressor BRCA1 functions during the DNA damage response.Nucleic Acids Res. 2013; 41:5784-98.

37. Bosselut R. Pleiotropic Functions of H3K27Me3 Demethylases in Immune Cell Differentiation.Trends Immunol. 2016; 37:102-13.

38. Kravtsova-Ivantsiv Y, Shomer I, Cohen-Kaplan V, Snijder B, Superti-Furga G, Gonen H, Sommer T, Ziv T, Admon A, Naroditsky I, Jbara M, Brik A, Pikarsky E, Kwon YT, et al. KPC1-mediated ubiquitination and proteasomal processing of NF- $\mathrm{kB} 1 \mathrm{p} 105$ to p50 restricts tumor growth.Cell. 2015; 161:333-47.

39. Saint-Léger A, Koelblen M, Civitelli L, Bah A, Djerbi N, Giraud-Panis MJ, Londoño-Vallejo A, Ascenzioni F, Gilson E. The basic N-terminal domain of TRF2 limits recombination endonuclease action at human telomeres. Cell Cycle. 2014; 13:2469-74.

40. Porro A, Feuerhahn S, Lingner J. TERRA-reinforced association of LSD1 with MRE11 promotes processing of uncapped telomeres.Cell Rep. 2014; 6:765-76.

41. $\mathrm{Hu} \mathrm{Pu}$, Qidi Zheng, Haiyan Li, Mengying Wu, Jiahui An, Xin Gui, Tianming Li, Dongdong Lu. CUDR promotes liver cancer stem cell growth through upregulating TERT and C-Myc. Oncotarget 2015; 6:40775-40798. doi: 10.18632/ oncotarget.5805.

42. Kibe T, Zimmermann M, de Lange T. TPP1 Blocks an ATRMediated Resection Mechanism at Telomeres.Mol Cell. 2016; 61:236-46.

43. Frescas D, de Lange T. TRF2-tethered TIN2 can mediate telomere protection by TPP1/POT1.Mol Cell Biol. 2014; 34:1349-62

44. He X, Bao W, Li X, Chen Z, Che Q, Wang H, Wan XP. The long non-coding RNA HOTAIR is upregulated in endometrial carcinoma and correlates with poor prognosis. Int J Mol Med. 2014; 33:325-32.

45. Zhang JX, Han L, Bao ZS, Wang YY, Chen LY, Yan W, Yu SZ, Pu PY, Liu N, You YP, Jiang T, Kang CS. HOTAIR, a cell cycle-associated long noncoding RNA and a strong predictor of survival, is preferentially expressed in classical and mesenchymal glioma.Neuro Oncol. 2013; 15:1595-603

46. Ge XS, Ma HJ, Zheng XH, Ruan HL, Liao XY, Xue WQ, Chen YB, Zhang Y, Jia WH. HOTAIR, a prognostic factor in esophageal squamous cell carcinoma, inhibits WIF-1 expression and activates Wnt pathway.Cancer Sci. 2013; 104:1675-8

47. Dong L, Hui L. HOTAIR Promotes Proliferation, Migration, and Invasion of Ovarian Cancer SKOV3 Cells Through Regulating PIK3R3.Med Sci Monit. 2016; 22:325-31 